\title{
过渡金属催化的芳环磺酰胺化反应研究进展
}

\author{
欧阳班来* 郑燕霞夏克坚 徐小玲王艺 \\ (南昌师范学院 南昌 330032)
}

\begin{abstract}
摘要 $N$-芳基磺酰胺骨架广泛存在于具有生物活性的分子中, 在医药领域有十分重要的应用. 因此研究 $N$-芳基磺酰胺 类化合物的合成方法受到了人们的广泛关注. 近年来过渡金属催化的卤代芳烃、芳基硼酸和 $\mathrm{C}_{\mathrm{Ar}}-\mathrm{H}$ 键的磺酰胺化反应 得到了快速发展，为 $N$-芳基磺酰胺类化合物的合成提供了高效、绿色的方法. 按照芳基源、过渡金属催化剂、配体和 磺酰胺化试剂进行分类, 综述了过渡金属催化的芳环磺酰胺化反应的最新研究进展, 并对此类反应的研究方向进行了 展望.
\end{abstract}

关键词 $N$-芳基磺酰胺; 磺酰胺化; 过渡金属催化; $\mathrm{C}-\mathrm{N}$ 键构建; $\mathrm{C}-\mathrm{H}$ 键活化

\section{Recent Progress in Transition Metal Catalyzed Sulfonamidation of Aromatic Compounds}

\author{
Ouyang, Banlai* Zheng, Yanxia Xia, Kejian Xu, Xiaoling Wang, Yi \\ (Department of Chemistry, Nanchang Normal University, Nanchang 330032)
}

\begin{abstract}
The $N$-arylsulfonamide group is an important moiety in medicinal chemistry because of its presence in many useful molecules with potential bioactivities. As a result, the development of synthetic routes to $N$-arylsulfonamides has been actively investigated. In recent years, the transition metal-catalyzed sulfonamidations of aryl halides, arylboronic acids and $\mathrm{C}_{\mathrm{Ar}}-\mathrm{H}$ bonds have extensively investigated, providing more efficient and environmentally friendly procedures for the synthesis of $\mathrm{N}$-arylsulfonamides. The recent progress in the transition metal-catalyzed sulfonamidation reactions is reviewed. The aromatic substrates, transition metal-catalysts, ligands, sulfonamidating reagents, mechanisms of the sulfonamidation reactions are mainly discussed. Finally, the future development of them is also prospected.
\end{abstract}

Keywords $\mathrm{N}$-arylsulfonamides; sulfonamidation; transition metal-catalyzed; $\mathrm{C}-\mathrm{N}$ bond construction; $\mathrm{C}-\mathrm{H}$ bond activation

$N$-芳基磺酰胺骨架广泛存在于具有生物活性的分 子中，在医药领域具有十分重要的应用. 例如，含有对 氨基磺酰胺骨架的磺胺类药物是第一类人工合成的抗 菌药, 在抗菌药发展历史上具有重要的地位, 此外, $N$ 芳基磺酰胺类化合物还被广泛应用于消炎镇痛、抗肿 瘤、抗病毒、抗寄生虫、抗癫㾁、利尿等领域 ${ }^{[1]}$. 因此, $N$ 芳基磺酰胺类化合物的合成方法研究受到了人们的广 泛关注.

芳香胺与磺酰氯的亲核取代反应是合成 $N$-芳基磺 酰胺的经典方法, 但磺酰氯和芳香胺的基因毒性使该方 法在磺酰胺类药物的合成中受到一定的限制 ${ }^{[2]}$. 此外, 当使用的芳胺为伯胺时, 该方法往往得到单磺酰芳香胺
和双磺酰芳香胺的混合物 ${ }^{[3]}$, 从而使反应的效率大大降 低. 近年来过渡金属催化的卤代芳烃、芳基硼酸和 $\mathrm{C}_{\mathrm{Ar}}-\mathrm{H}$ 键的磺酰胺化反应得到快速发展, 为 $\mathrm{N}$-芳基磺 酰胺类化合物的合成提供了更高效、更绿色的方法. 本 文从芳基源、过渡金属催化剂、磺酰胺化试剂、反应机 理等方面系统阐述过渡金属催化的芳环磺酰胺化反应 的最新研究进展.

\section{1 卤代芳烃的磺酰胺化反应}

\section{1 钯催化卤代芳烃与磺酰胺的偶联反应}

过渡金属催化卤代芳烃与胺类化合物的交叉偶联 反应是构建 $\mathrm{C}-\mathrm{N}$ 键的重要方法之一, 包括钯催化的

\footnotetext{
* Corresponding author. E-mail: blouyang@qq.com

Received October 5, 2019; revised December 16, 2019; published online January 3, 2020

Project supported by the Open Project Program of Key Laboratory of Functional Small Organic Molecule, Ministry of Education, Jiangxi Normal University (No. KLFS-KF-201721) and the Science and Technology Project of the Education Department of Jiangxi Province (No. GJJ161235).

江西师范大学功能有机小分子教育部重点实验室开放课题(No. KLFS-KF-201721)和江西省教育厅科学技术研究(No. GJJ161235)资助项目.
} 
Buchwald-Hartwig 偶联反应 ${ }^{[4]}$ 和铜催化的 Ullmann 型 $\mathrm{C}-\mathrm{N}$ 偶联反应 ${ }^{[5]}$. 由于磺酰胺较弱的亲核性, 卤代芳烃 (特别是氯代芳烃)与磺酰胺的偶联反应较难进行.

1996 年 Buchwald 课题组 ${ }^{[6]}$ 以钯络合物为催化剂,首 次实现了溴代芳烃与磺酰胺的分子内偶联反应(Scheme 1). 该反应以 $\mathrm{Pd}_{2}(\mathrm{dba})_{3}$ 为催化剂, 三(邻甲基苯基)膦为 配体, $\mathrm{K}_{2} \mathrm{CO}_{3}$ 为碱，甲苯为溶剂，产率最高可达 $88 \%$.

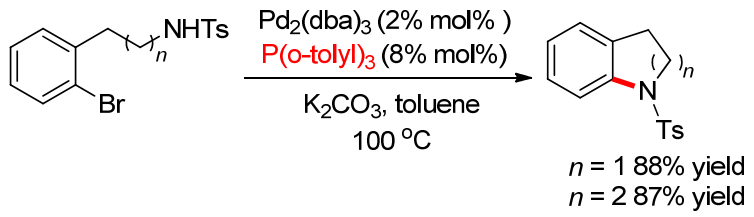

图式 1 钯催化分子内澳代芳烃与磺酰胺的偶联反应 Scheme 1 Palladium-catalyzed intramolecular coupling of aryl bromides with sulfonamides

2000 年 Buchwald 课题组 ${ }^{[7]}$ 以 $\mathrm{Pd}(\mathrm{OAc})_{2}$ 为催化剂, Xantphos 为配体, 在相对温和的条件下高产率地实现了 溴代芳烃与磺酰胺的交叉偶联反应(Scheme 2). 作者通 过 X-ray 单晶衍生实验证明，该反应通过中间体 1 进行, 且双膦配体与钯的络合方式为 trans.

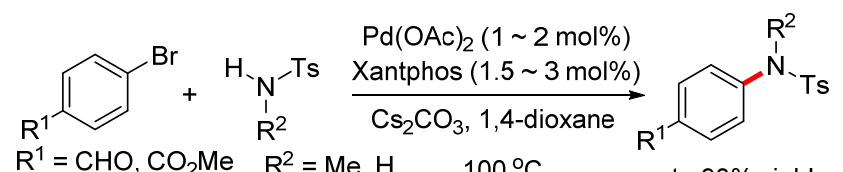
$\mathrm{R}^{1}=\mathrm{CHO}, \mathrm{CO}_{2} \mathrm{Me} \quad \mathrm{R}^{2}=\mathrm{Me}, \mathrm{H} \quad 100^{\circ} \mathrm{C} \quad$ up to $93 \%$ yield<smiles>Pc1ccc2c(c1P)Oc1c(P)cccc1C2</smiles>

Xantphos

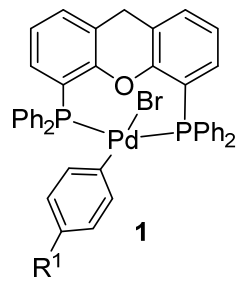

图式 2 Xantphos 为配体的钯催化溴代芳烃与磺酰胺的交叉 偶联反应

Scheme 2 Xantphos-promoted palladium-catalyzed cross coupling of aryl bromides with sulfonamides

由于氯代芳烃的低反应活性, 其参与的磺酰胺化和 酰胺化反应较难进行. 2003 年, Cao 课题组 ${ }^{[8]}$ 发现微波能 有效地促进钯催化氯代芳烃与磺酰胺的交叉偶联反应, 该反应使用了联苯类 N,P-双齿配体 2, 钯催化剂的用量 低至 $1 \mathrm{~mol} \%$ ，产率最高可达 $82 \%$ ，带有吸电子基团的氯 代芳烃和氯代杂环化合物均适用于该反应(Scheme 3).

2007 年, Buchwald 课题组 ${ }^{[9]}$ 发现联苯类单齿膦配体 也适用于钯催化的氯代芳烃与磺酰胺、酰胺的交叉偶联 反应. 例如, 以 $\mathrm{Pd}_{2}(\mathrm{dba})_{3}$ 为催化剂, $\mathrm{Me}_{4} t-\mathrm{BuXPhos}$ 为配 体, $\mathrm{K}_{3} \mathrm{PO}_{4}$ 为碱, 叔丁醇为溶剂, 对氯甲苯与苯磺酰胺能 顺利进行交叉偶联, 产率达到 87\% (Scheme 4).

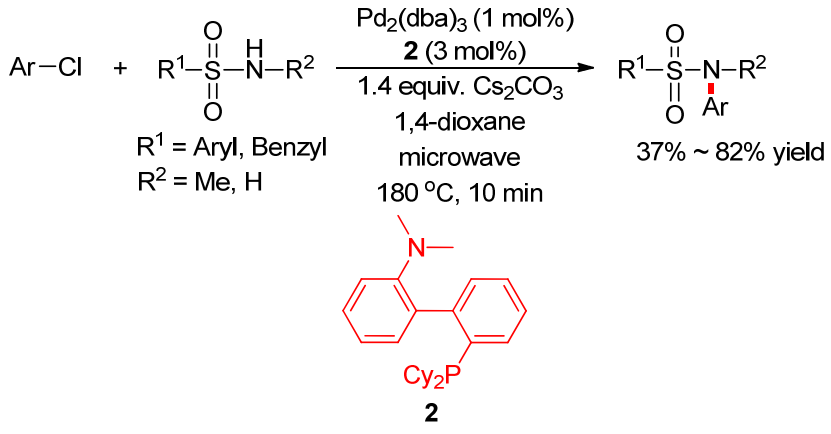

图式 3 微波促进的钯催化氯代芳烃与磺酰胺的交叉偶联反 应

Scheme 3 Microwave-assisted palladium-catalyzed crosscoupling of aryl chlorides with sulfonamides

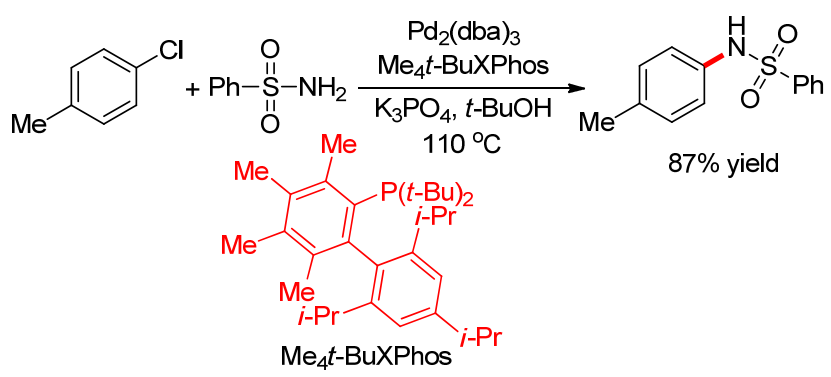

图式 4 单齿配体 $\mathrm{Me}_{4} t-\mathrm{BuXPhos}$ 促进的钯催化氯代芳烃的磺 酰胺化反应

Scheme $4 \quad \mathrm{Me}_{4} t$-BuXPhos-assisted palladium-catalyzed crosscoupling of aryl chlorides with sulfonamides

随后该课题组 ${ }^{[10]}$ 对此类膦配体进行了深入的研究, 合成了一系列含联苯结构的单齿膦配体 4 , 对其催化活 性的研究表明, 该系列膦配体能有效促进钯催化氯代芳 烃( $\operatorname{ArX}) 、$ 三氟甲磺酸芳酯( $\mathrm{ArOTf})$ 等与酰胺、磺酰胺的 偶联反应, 其中 $4 \mathrm{a}$ 的催化活性最为突出. 例如, [Pd(allyl) $\mathrm{Cl}]_{2} / \mathbf{4 a}$ 催化体系能顺利催化对氯苯甲酸甲酯与磺 酰胺 3 的偶联反应，产率达到 87\% (Scheme 5).

2011 年, Ruble 课题组 ${ }^{[11]}$ 对钯催化的卤代芳烃与磺 酰胺的偶联反应进行了系统的研究, 发展了以氯化烯丙 基钯(II)二聚物([Pd(allyl) $\mathrm{Cl}]_{2}$ ) 为钯源, $t$-BuXPhos 为配体, 廉价的 $\mathrm{K}_{2} \mathrm{CO}_{3}$ 为碱, 2-甲基四氢呋喃为溶剂的反应体系. 与之前的反应体系相比, 该反应体系具有试剂更廉价、 反应条件更温和、底物适用范围更广泛、反应产率更高 等优点(Scheme 6).

2019 年 Shashank 课题组 ${ }^{[12]}$ 对上述联芳基膦配体作 了进一步的优化，设计并合成了一系列联芳基环膦配体 5a $\sim 5 k$, 研究表明此类配体能够非常高效地促进钯催化 的卤代芳烃(卤代杂芳烃)与磺酰胺的交叉偶联反应. 例 如, 以 $0.1 \mathrm{~mol} \% \mathrm{Pd}_{2}(\mathrm{dba})_{3}$ 为催化剂, $\mathbf{5 j}$ 为配体, 6-溴喹啉 与 4-三氟甲基苯磺酰胺的偶联反应的产率高达到 $92 \%$ (Scheme 7). 


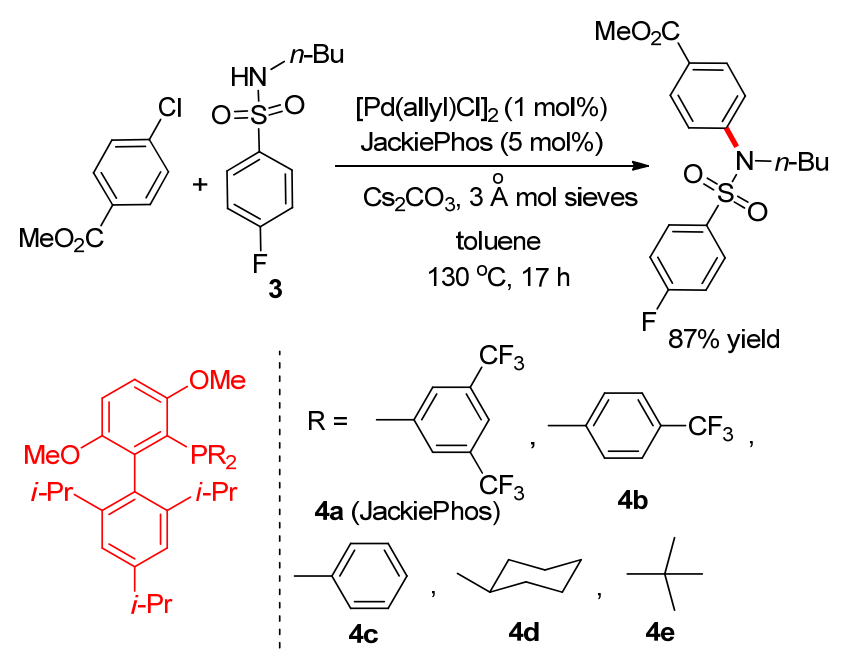

图式 5 JackiePhos 促进的钯催化氯代芳烃的磺酰胺化反应 Scheme 5 JackiePhos-assisted palladium-catalyzed cross-coupling of aryl chlorides with sulfonamides

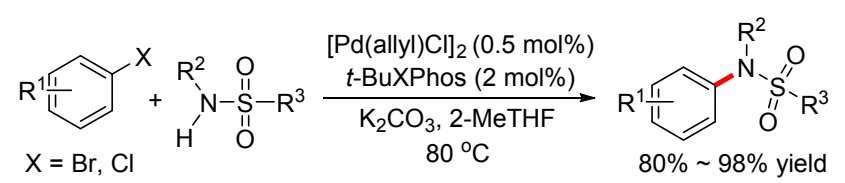
$\mathrm{R}^{1}=\mathrm{H}, \mathrm{Me}, \mathrm{OMe}, \mathrm{CN}$, etc.; $\mathrm{R}^{2}=\mathrm{Me}, \mathrm{H} ; \mathrm{R}^{3}=$ Alkyl, Aryl

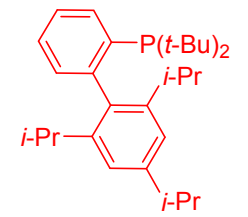

$t$-BuXPhos

图式 $6 t$-BuXPhos 促进的钯催化卤代芳烃与磺酰胺的偶联反 应

Scheme $6 t$-BuXPhos-assisted palladium-catalyzed cross-coupling of aryl chlorides with sulfonamides

\section{2 铜催化卤代芳烃的磺酰胺化反应}

与钯催化的偶联反应相比, 铜催化的偶联反应具有 催化剂更加廉价、无需使用昂贵、高毒性的膦配体等优 点, 因此铜催化的 $\mathrm{C}-\mathrm{N}$ 偶联反应受到有机合成工作者 的广泛关注, 但传统的铜催化 $\mathrm{C}-\mathrm{N}$ 偶联反应的反应条 件非常苛刻，使其在工业上的应用受到了很大的限制.

2003 年, $\mathrm{Wu}$ 课题组 ${ }^{[13]}$ 首次报道了铜催化溴代芳烃 和碘代芳烃与磺酰胺的交叉偶联反应. 该反应以 $\mathrm{CuI}$ 为 催化剂, $\mathrm{K}_{2} \mathrm{CO}_{3}$ 为碱, $N$-甲基吡咯烷酮为溶剂, 无需添加 配体. 与传统的 Ullmann 反应不同, 该反应采用微波加 热代替传统加热方式使反应产率大大提高, 最高可达到 90\%. 该反应具有较好的底物普适性, 各类具有吸电子 和给电子基的碘代芳烃和溴代芳烃均能顺利反应, 但该 催化体系不适合于氯代芳烃(Scheme 8).

之后, Teo 课题组 ${ }^{[14]}$ 也报道了一例无配体参与的铜 催化溴代芳烃和碘代芳烃的磺酰胺化反应. 该反应以

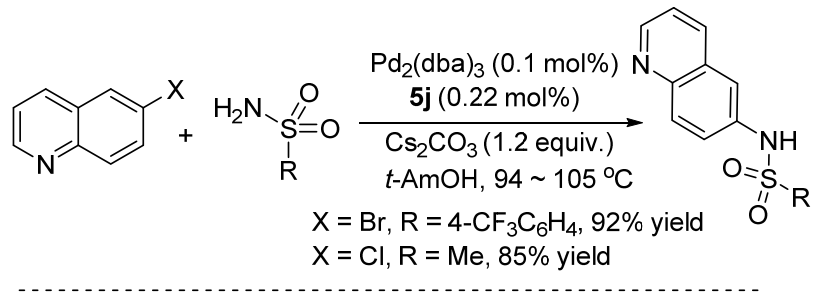

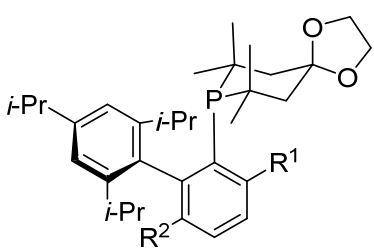

5a: $R^{1}=R^{2}=H$

5b: $\mathrm{R}^{1}=\mathrm{OMe}, \mathrm{R}^{2}=\mathrm{H}$

5c: $\mathrm{R}^{1}=\mathrm{R}^{2}=\mathrm{OMe}$

$5 d: R^{1}=O M e, R^{2}=M e$

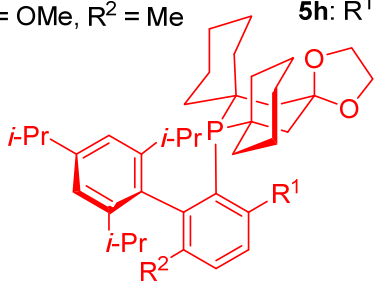

5i: $\mathrm{R}^{1}=\mathrm{R}^{2}=\mathrm{H}$

5j: $R^{1}=O M e, R^{2}=H$

5k: $\mathrm{R}^{1}=\mathrm{R}^{2}=\mathrm{OMe}$

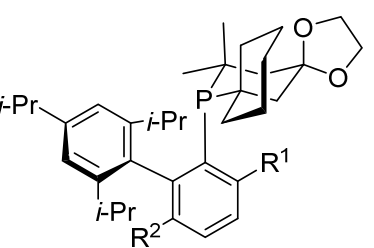

5f: $\mathrm{R}^{1}=\mathrm{OMe}, \mathrm{R}^{2}=\mathrm{H}$

5g: $\mathrm{R}^{1}=\mathrm{R}^{2}=\mathrm{OMe}$

5h: $\mathrm{R}^{1}=\mathrm{OMe}, \mathrm{R}^{2}=\mathrm{Me}$ 5e: $R^{1}=R^{2}=H$

图式 7 联芳基环膦配体促进的钯催化卤代芳烃与磺酰胺的 偶联反应

Scheme 7 Pd-catalyzed cross-coupling reactions promoted by biaryl phosphorinane ligands

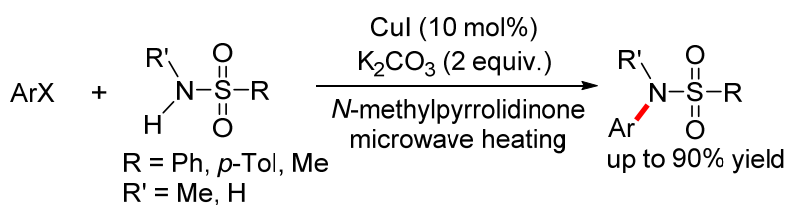

图式 8 微波促进的铜催化卤代芳烃与磺酰胺的偶联反应

Scheme 8 Microwave-assisted copper-catalyzed cross-coupling of aryl halides with sulfonamides

$\mathrm{Cu}_{2} \mathrm{O}$ 为催化剂, $\mathrm{Cs}_{2} \mathrm{CO}_{3}$ 为碱, $\mathrm{H}_{2} \mathrm{O}$ 为反应溶剂, 具有反 应试剂廉价易得、反应溶剂绿色的优点，但反应温度较 高，不适用于氯代芳烃(Scheme 9).

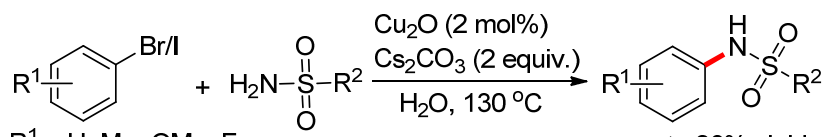

$\mathrm{R}^{1}=\mathrm{H}, \mathrm{Me}, \mathrm{OMe}, \mathrm{F}, \quad \mathrm{R}^{2}=\mathrm{Alkyl}$

up to $90 \%$ yield

图式 9 水相中铜催化卤代芳烃的磺酰胺化反应

Scheme 9 Copper-catalyzed cross-coupling of aryl halides with sulfonamides in water

适当配体的加入能大大的促进铜催化的 $\mathrm{C}-\mathrm{N}$ 偶联 反应. 2005 年, 郭庆祥课题组 ${ }^{[15]}$ 报到了以 $\alpha$-氨基酸 6 为 配体的 $\mathrm{CuI}$ 催化的溴代芳烃、碘代芳烃与磺酰胺的偶联 
反应. 该反应 $\mathrm{K}_{3} \mathrm{PO}_{4}$ 为碱, $\mathrm{DMF}$ 为溶剂, 具有反应产率 高和底物普适性广的优点, 但反应的温度比较高. 作者 根据前人的报道提出了如 Scheme 10 所示的 $\mathrm{Cu}(\mathrm{I})-$ $\mathrm{Cu}(\mathrm{III})-\mathrm{Cu}(\mathrm{I})$ 的催化机制. 之后, 其他课题组分别将 $N, N$-双齿配体 $\mathbf{7}^{[16]} 、 \boldsymbol{8}^{[17]}$ 及四齿配体 $\mathbf{9}^{[18]}$ 应用于铜催化卤 代芳烃和卤代杂环化合物的磺酰胺化反应, 发展了条件 更温和、试剂更廉价易的磺酰胺化催化体系(Scheme $10)$.

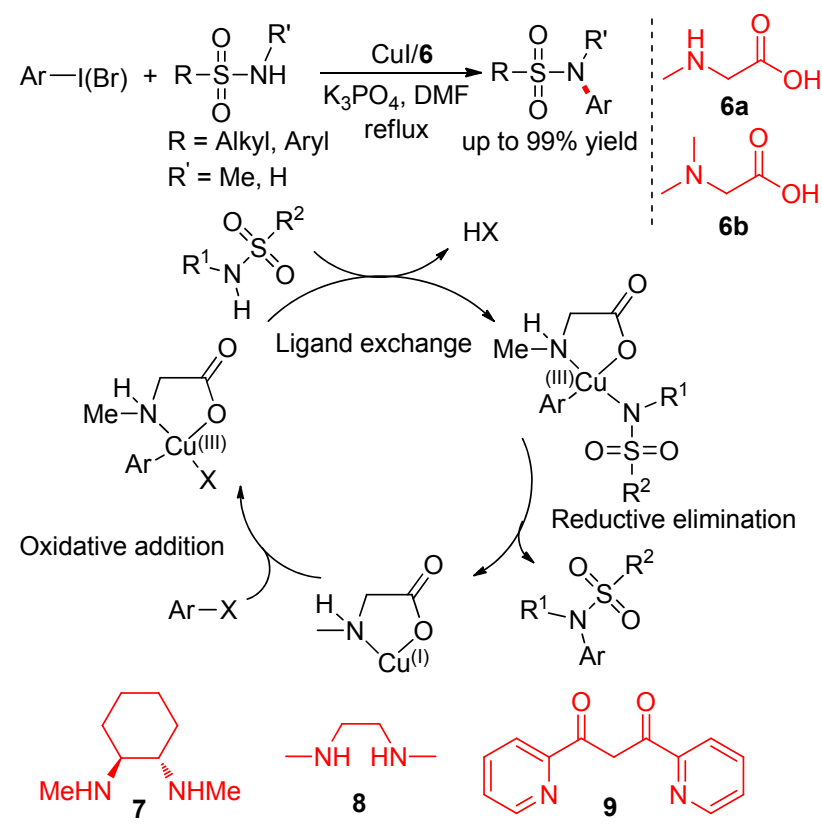

图式 10 配体促进的铜催化卤代芳烃与磺酰胺的偶联反应 Scheme 10 Ligand-assisted copper-catalyzed cross-coupling of aryl halides with sulfonamides

\section{3 镍催化卤代芳烃的磺酰胺化反应}

钯和铜催化的芳香卤代烃与磺酰胺的偶联反应得 到了深入的研究, 而关于镍催化的 $\mathrm{C}-\mathrm{N}$ 偶联反应的报 道较少, 虽然镍具有储量丰富和廉价易得的优点, 主要 原因是催化循环中关键 $\mathrm{Ni}^{\mathrm{II}}$ 中间体的 $\mathrm{C}-\mathrm{NR}_{2}$ 还原消除反 应较难进行, 2017 年 MacMillan 课题组 ${ }^{[19]}$ 利用光诱导的 方法成功地解决了该问题, 发展了光诱导镍催化的芳基 溴和杂芳基澳与磺酰胺的交叉偶联反应. 该反应具有反 应条件温和、反应效率高和底物适用范围广等优点. 其 反应机理包括镍催化循环和光诱导循环, $\mathrm{Ni}^{0}$ 络合物 $\mathbf{1 0}$ 与溴苯进行氧化加成反应产生 $\mathrm{Ni}^{\mathrm{II}}$ 中间体 11, 在碱的作 用下与磺酰胺进行配体交换产生中间体 $\mathbf{1 2}$, 接着从激 发态的 ${ }^{*} \mathrm{Ir}^{\mathrm{III}}$ 中获得能量生成激发态的中间体*12, 进而 发生还原消除得到目标产物并使催化剂再生. 激发态的 * Ir ${ }^{\mathrm{III}}$ 失去能量后生成基态的 $\mathrm{Ir}^{\mathrm{III}}$, 重新获取光能后产生 激发态*Ir III, 从而实现光诱导循环(Scheme 11).

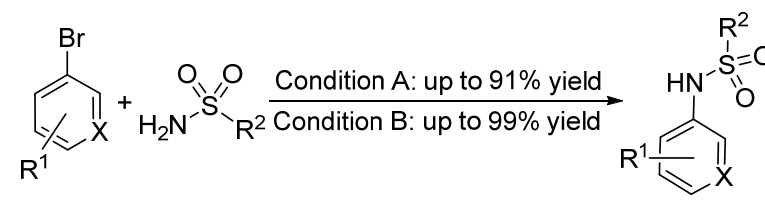

$\mathrm{R}^{1}=\mathrm{H}, \mathrm{SMe}, \mathrm{OMe}, \mathrm{Me}, i-\mathrm{Bu}, \mathrm{F}, \mathrm{Cl}, \mathrm{CONHMe}, \mathrm{CF}_{3}, \mathrm{CN}$, etc. $\mathrm{R}^{2}=$ aryl, alkyl, heteroaryl; $\mathrm{X}=\mathrm{CH}, \mathrm{N}$

$\begin{array}{ll}\text { Condition A: } & \text { Condition B: } \\ \operatorname{Ir}(\text { ppy })_{2}(\text { bpy }) \mathrm{PF}_{6}(0.05 \mathrm{~mol} \%) & \operatorname{Ir}(\mathrm{ppy})_{2}(\mathrm{dtbbpy}) \mathrm{PF}_{6}(0.05 \mathrm{~mol} \%) \\ \mathrm{NiCl}_{2} \cdot \mathrm{glyme} & \mathrm{NiCl}_{2} \cdot \text { glyme, } 1 \mathrm{~mol} \% \mathrm{dtbbpy} \\ \mathrm{TMG}, \mathrm{MeCN}, 68{ }^{\circ} \mathrm{C} & \mathrm{TMG}, \mathrm{DMSO}, 25{ }^{\circ} \mathrm{C} \\ \text { blue LED, 24 } \mathrm{h} & \text { blue LED, 48 } \mathrm{h}\end{array}$

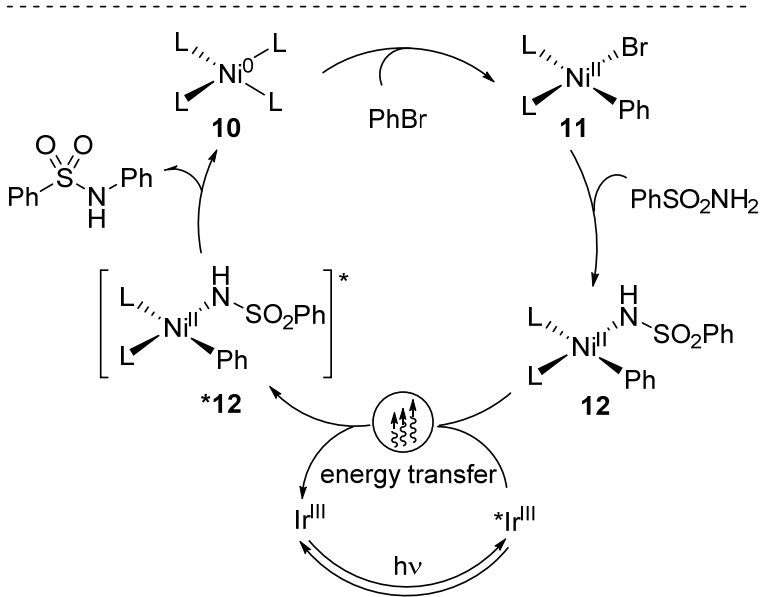

图式 11 光诱导镍催化芳基卤和杂芳基卤的磺酰胺化反应 Scheme 11 Sulfonamidation of aryl and heteroaryl halides through photosensitized Nickel catalysis

\section{2 芳基硼酸的磺酰胺化反应}

铜催化下以芳基硼酸为芳基供体的 $\mathrm{C}-\mathrm{N}$ 偶联反应 被称之为 Chan-Lam 偶联反应, 是构建 $\mathrm{C}-\mathrm{N}$ 键的另一种 高效的方法. 与 Buchwald-Hartwig 偶联反应和 Ullmann 型 $\mathrm{C}-\mathrm{N}$ 偶联反应相比,Chan-Lam 偶联反应具有催化剂 便宜、反应条件温和、无需配体、操作简便、可在空气 中进行等优点 ${ }^{[20,21]}$.

1998 年, Chan 课题组 ${ }^{[22]}$ 发现以等物质的量的 $\mathrm{Cu}(\mathrm{OAc})_{2}$ 为催化剂, $\mathrm{Et}_{3} \mathrm{~N}$ 为碱, 二氯甲烷为溶剂, 芳基 硼酸与磺酰胺的偶联反应能在室温下进行, 产率中等. 与传统过渡金属催化的偶联反应不同，该反应中的磺酰 胺和芳基硼酸为亲核试剂，需要使用等物质的量 $\mathrm{Cu}(\mathrm{OAc})_{2}$ 才能使反应顺利进行(Scheme 12).

2001 年, Lam 课题组 ${ }^{[23]}$ 报道了催化量铜促进的芳基 硼酸的磺酰胺化反应. 该反应以 $\mathrm{Cu}(\mathrm{OAc})_{2}$ 为催化剂, 清 洁的 $\mathrm{O}_{2}$ 为氧化剂, 于室温下进行, 产率中等, 但底物的 普适性较差(Scheme 13). 随后, 多个课题组对该反应体 系进行了改进, 发展了分别以甲醇 ${ }^{[24]}$ 、异丙醇 ${ }^{[25]}$ 、离子 液 ${ }^{[26]}$ 、水 ${ }^{[27]}$ 等为溶剂的铜催化芳基硼酸的磺酰胺化反 应，但此类反应体系普遍存在着催化剂用量大 $(10 \mathrm{~mol} \%$ 以上)、反应时间长、底物普适性差等缺点. 


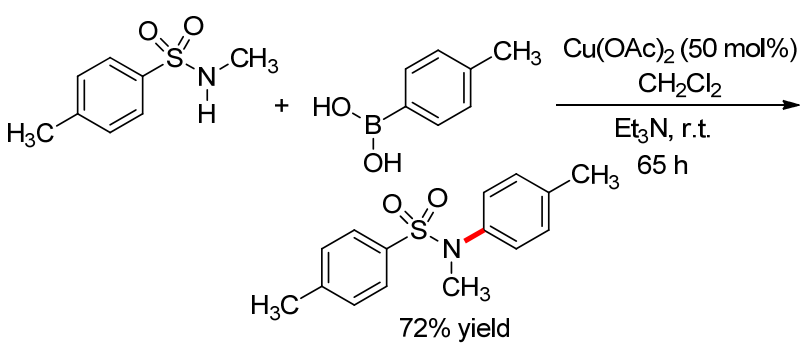

图式 12 等物质的量铜促进的芳基硼酸与磺酰胺的偶联反应 Scheme 12 Cross-coupling of arylboronic acids with sulfonamides catalyzed by a stoichiometric amount of copper

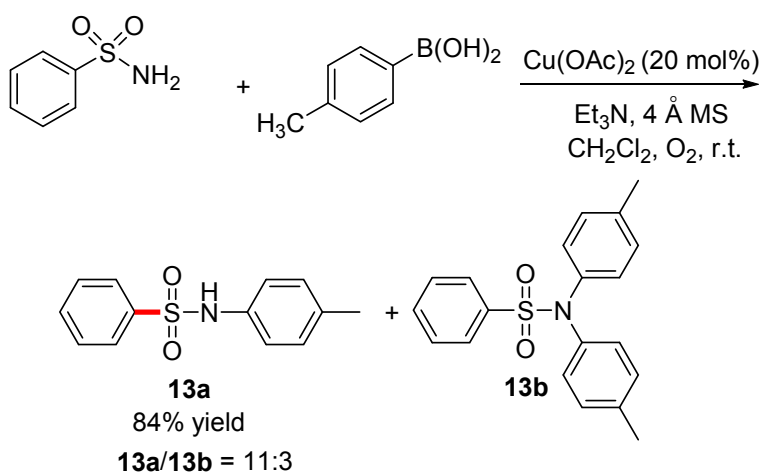

图 13 催化量的铜促进的芳基硼酸的磺酰胺化反应

Scheme 13 Cross-coupling of arylboronic acids with sulfonamides catalyzed by a catalytic amount of copper

2018 年 Leitch 课题组 ${ }^{[28]}$ 利用电子顺磁共振谱和紫 外可见光分析法对 $N$-芳基磺酰胺与芳基硼酸的 ChanLam 偶联反应的机理进行了系统的研究, 提出了 $\mathrm{Cu}(\mathrm{I})-$ $\mathrm{Cu}(\mathrm{II})-\mathrm{Cu}(\mathrm{III})-\mathrm{Cu}(\mathrm{I})$ 的铜催化循环机制. 在此基础上发 现 $\mathrm{Cu}(\mathrm{MeCN})_{4} \mathrm{PF}_{6} / N$-甲基哌啶催化体系能高效地催化芳 基硼酸与 $N$-芳基磺酰胺的偶联反应, $\mathrm{Cu}(\mathrm{MeCN})_{4} \mathrm{PF}_{6} /$ $\mathrm{K}_{3} \mathrm{PO}_{4}$ 组合能有效地催化芳基嗍酸频哪醇酯与 $N$-芳基 磺酰胺的偶联反应. 这两个催化体系均具有反应条件温 和、催化效率高、适合于放大反应等优点, 缺点是催化 剂的用量比较大(Scheme 14).

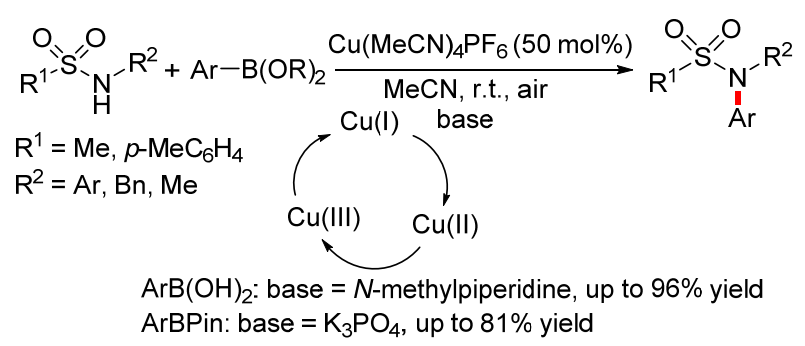

图式 $14 \mathrm{Cu}(\mathrm{MeCN})_{4} \mathrm{PF}_{6}$ 催化的 $N$-芳基磺酰胺与芳基嗍酸的 Chan-Lam 偶联反应

Scheme $14 \mathrm{Cu}(\mathrm{MeCN})_{4} \mathrm{PF}_{6}$ catalyzed Chan-Lam $N$-arylation of $\mathrm{N}$-aryl sulfonamides

传统的芳基硼酸的磺酰胺化反应通过外加氧化剂
使 $\mathrm{Cu}(\mathrm{I})-\mathrm{Cu}(\mathrm{II})-\mathrm{Cu}(\mathrm{III})-\mathrm{Cu}(\mathrm{I})$ 催化循环得以顺利进行. 2014 年 Kim 课题组 ${ }^{[29]}$ 报道了以磺酰叠氮为氮源的芳基 硼酸的磺酰胺化反应, 该反应以 $\mathrm{CuCl}$ 为催化剂, 甲醇 为溶剂, 无需碱和外加氧化剂, 室温下反应, 产率最高 达 99\%, 且具有非常好的底物普适性，但叠氮化合物潜 在的易爆性将使该反应在工业上的应用受到限制 (Scheme 15).

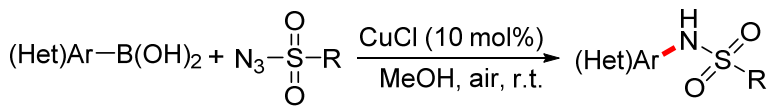

$$
\begin{aligned}
& \mathrm{R}=\text { Aryl, Alkyl }
\end{aligned}
$$

图式 15 基于磺酰叠氮的芳基硼酸的磺酰胺化反应 Scheme 15 Sulfonamidation of arylboronic acids with sulfonyl Azides

2018 年我们课题组 ${ }^{[30]}$ 发展了以氯胺盐为氮源的芳 基喼酸的磺酰胺化反应. 该反应以廉价的醋酸铜为催化 剂, 叔丁醇钾为碱，乙醇为溶剂，于室温下进行，产率 最高可达 $73 \%$. 该反应具有催化剂用量低，反应条件温 和，操作简单，底物普适性强等优点(Scheme 16). 氯胺 盐具有性质稳定、廉价易得的优点, 因此以氯胺盐为氮 源的芳基嗍酸的磺酰胺化反应更适合工业生产. 随后, 我们对该反应进行了进一步的优化, 发展了水相中铜催 化以氯胺盐为氮源的芳基硼酸的磺酰胺化反应 ${ }^{[31]}$.

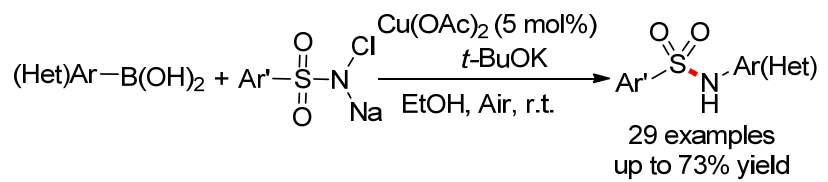

图式 16 以氯胺盐为氮源的芳基硼酸的磺酰胺化反应 Scheme 16 Sulfonamidation of arylboronic acids with chloramine salts

\section{3 过渡金属催化的 $\mathrm{C}_{\mathrm{Ar}}-\mathrm{H}$ 氧化偶联反应}

$\mathrm{C}-\mathrm{H}$ 键广泛存在于各类有机化合物中, 其直接官 能团化构建新化学键, 能有效简化操作步骤, 减少副产 物的产生，符合绿色化学要求. 近十多年来，过渡金属 催化的 $\mathrm{C}-\mathrm{H}$ 键直接官能化构建 $\mathrm{C}-\mathrm{N}$ 键的研究已成为 热点 ${ }^{[32]}$.

\section{1 钯催化 $\mathrm{C}_{\mathrm{Ar}}-\mathrm{H}$ 键的氧化偶联反应}

2006 年, 支志明课题组 ${ }^{[33]}$ 报道了 $\mathrm{Pd}(\mathrm{OAc})_{2}$ 催化的 $O$-甲基豚的邻位 $\mathrm{C}-\mathrm{H}$ 键与磺酰胺的氧化偶联反应，该 反应以 $\mathrm{K}_{2} \mathrm{~S}_{2} \mathrm{O}_{8}$ 为氧化剂, 无需添加任何配体, 即可在相 对温和的条件下以中等产率得到目标产物. 作者对反应 机理进行了初步的研究, 认为反应经过了磺酰氮宾中间 体对 C-Pd 键的插入反应(Scheme 17). 


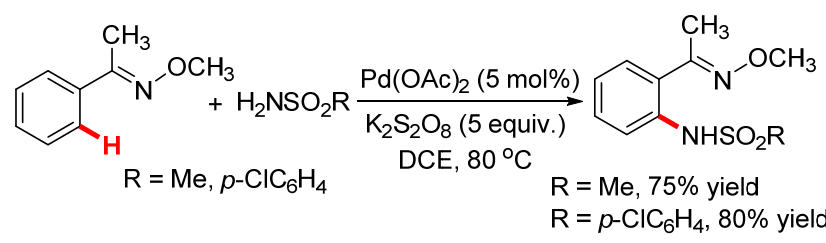

图式 17 钯催化的 $O$-甲基肜的邻位 $\mathrm{C}-\mathrm{H}$ 键磺酰胺化反应 Scheme 17 Pd-catalyzed ortho-sulfonamidation of aromatic oximes

2011 年, Youn 课题组 ${ }^{[34]}$ 同样以 $\mathrm{Pd}(\mathrm{OAc})_{2}$ 为催化剂, 改用 Oxone 为氧化剂, 对甲苯磺酸为添加剂, 成功实现 了分子内芳环 $\mathrm{C}-\mathrm{H}$ 键与磺酰胺的氧化偶联反应, 产率 最高可达 $98 \%$. 该反应在室温即可进行, 底物普适性强, 为咔唑类化合物的合成提供了一种非常高效的途径 (Scheme 18).

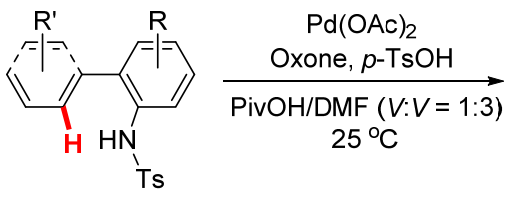

$\mathrm{R}=\mathrm{H}, \mathrm{Me}, \mathrm{CF}_{3}, \mathrm{NO}_{2}$ $\mathrm{R}^{\prime}=\mathrm{H}, \mathrm{MeO}, \mathrm{Cl}, \mathrm{Ac}, \mathrm{NO}_{2}$

图式 18 钯催化分子内 $\mathrm{C}-\mathrm{H}$ 键磺酰胺化反应 Scheme 18 Palladium-catalyzed intramolecular $\mathrm{C}-\mathrm{H}$ bond sulfonamidation reactions

与含氮基团导向的 $\mathrm{C}-\mathrm{H}$ 键官能团化相比, 羰基等 含氧基团导向的 $\mathrm{C}-\mathrm{H}$ 键官能团化反应往往更具挑战 性. 2011 年, 刘䂞课题组 ${ }^{[35]}$ 报道了钯催化芳香酮的邻位 $\mathrm{C}-\mathrm{H}$ 键与磺酰胺的氧化偶联反应. 该反应以 $\operatorname{Pd}(\mathrm{OTf})_{2}$ 为钯源, $\left[\mathrm{F}^{+}\right]$或 $\mathrm{Na}_{2} \mathrm{~S}_{2} \mathrm{O}_{8}$ 为氧化剂, 各类芳香酮均适合该 催化体系, 且具有较强给电子基团的酮反应效果更好. 其反应机理如 Scheme 19 所示, 芳香酮与 Pd(II)络合生 成钯环中间体 14, 接着与磺酰胺进行配体交换生成中 间体 15, 进而被氧化成四价钯中间体 16, 最后进行还原 消除得到目标产物并使催化剂得到再生.

\section{2 铜催化 $\mathrm{C}_{\mathrm{Ar}}$ - $\mathrm{H}$ 键的氧化偶联反应}

2006 年, 余金权课题组 ${ }^{[36]}$ 用等物质的量的 $\mathrm{Cu}-$ $(\mathrm{OAc})_{2}$ 实现了以磺酰胺为氮源的吡啶基导向的苯环邻 位 $\mathrm{C}$ - $\mathrm{H}$ 键直接磺酰胺化反应. 随后, Nicholas 课题组 ${ }^{[37]}$ 以氧气为氧化剂, 二甲基亚砜(DMSO)为添加剂把催化 剂的用量降低到了 $20 \mathrm{~mol} \%$, 但反应温度升高到了 $160{ }^{\circ} \mathrm{C}$, 且仅获得了中等产率. 作者提出了 $\mathrm{Cu}(\mathrm{II})-\mathrm{Cu}-$ (III)- $\mathrm{Cu}(\mathrm{I})-\mathrm{Cu}(\mathrm{II})$ 的催化机制, 首先 2-苯基吡啶与 $\mathrm{Cu}(\mathrm{II})$ 络合生成铜环中间体 17, 与磺酰胺进行配体交换产生 络合物 18, 进一步被氧气氧化成 $\mathrm{Cu}(\mathrm{III})$ 络合物 19 , 最后 通过还原消除生成目标产物和 $\mathrm{CuOAc}, \mathrm{CuOAc}$ 被氧气 氧化后重新生成 $\mathrm{Cu}(\mathrm{OAc})_{2}$ (Scheme 20).

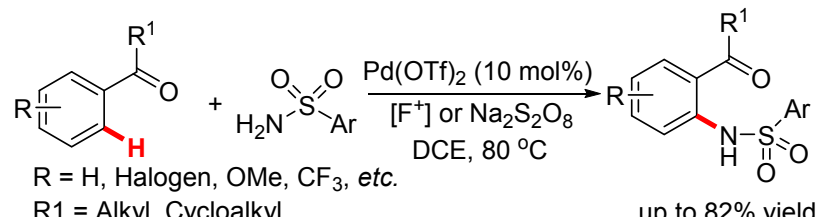
$\mathrm{R} 1=$ Alkyl, Cycloalkyl

up to $82 \%$ yield

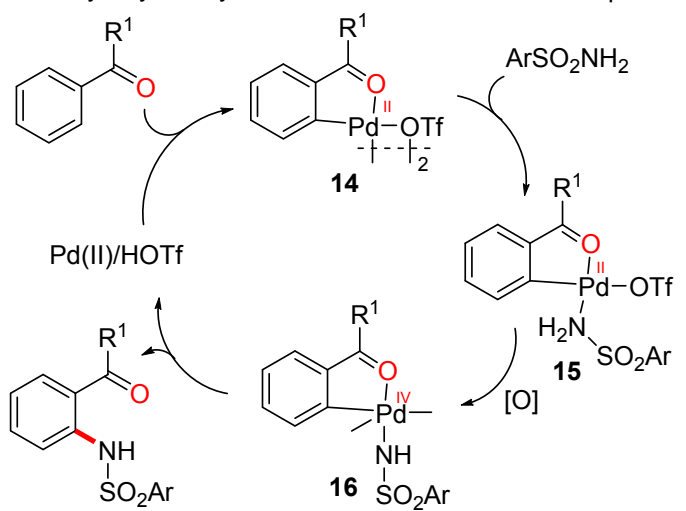

图式 19 钯催化羰基导向的邻位 $\mathrm{C}-\mathrm{H}$ 键磺酰胺化反应 Scheme 19 Pd-catalyzed ortho-C $-\mathrm{H}$ sulfonamidation of aromatic ketones
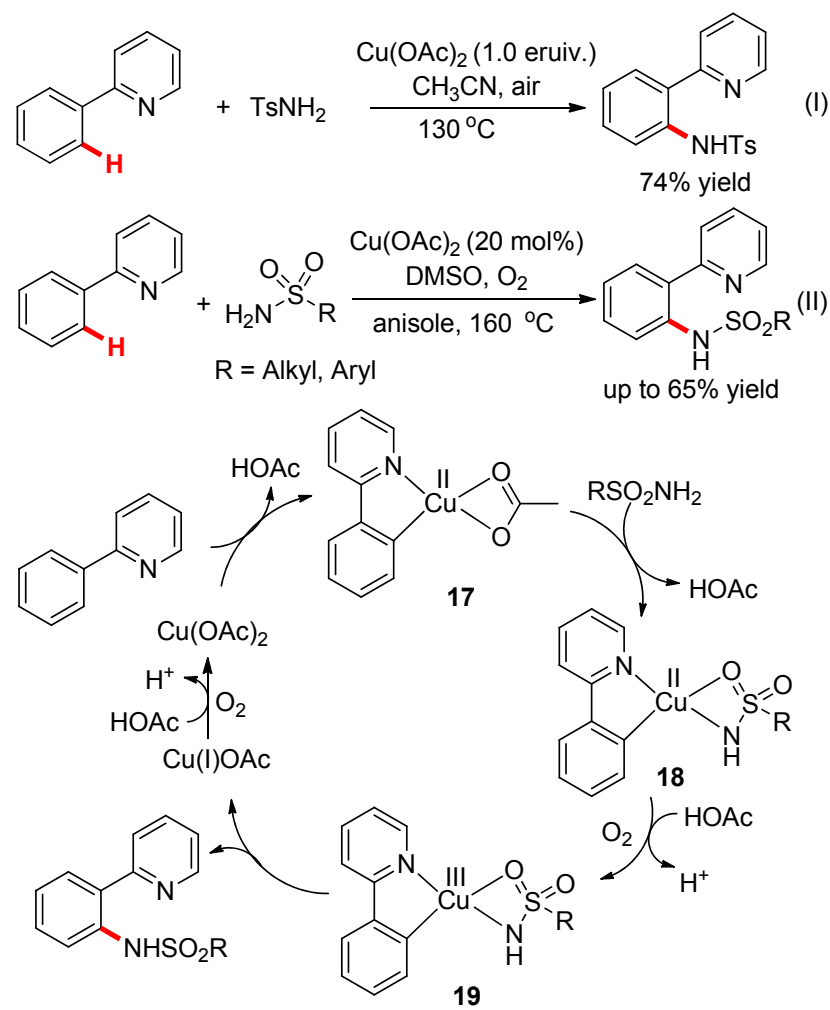

图式 20 铜催化以氧气为氧化剂的 2-苯基吡啶的 $\mathrm{C}_{\mathrm{Ar}}-\mathrm{H}$ 键磺 酰胺化反应

Scheme 20 Sulfonamidation of 2-phenylpyridine with oxygen as the terminal oxidant

导向基团的设计和合成一直是过渡金属催化 $\mathrm{C}_{\mathrm{Ar}}-$ $\mathrm{H}$ 键活化反应的研究重点. 2014 年，余金权课题组 ${ }^{[38]}$ 报 道了具有双络合位点的啞唑啉/酰胺基作为导向基的铜 催化 $\mathrm{C}-\mathrm{H}$ 键氧化偶联反应. 该反应具有反应条件相对 
温和、反应试剂绿色环保、反应底物普适性强等优点, 缺 点是需要使用物质的量的 $\mathrm{Cu}(\mathrm{OAc})_{2}$ (Scheme 21).

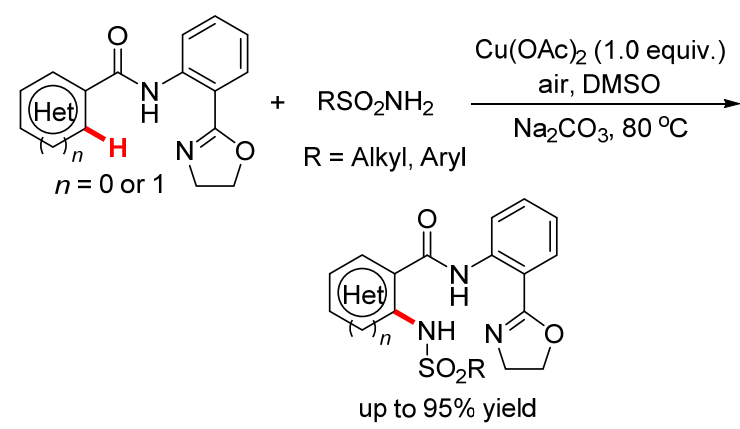

图式 21 铜催化噁唑啉/酰胺基导向的 $\mathrm{C}_{\mathrm{Ar}}-\mathrm{H}$ 键的磺酰胺化 反应

Scheme 21 Amide-tethered oxazoline-directed $\mathrm{C}-\mathrm{H}$ sulfonamidations

2016 年, $\mathrm{Li}$ 课题组 ${ }^{[39]}$ 以 $\mathrm{Cu}(\mathrm{OAc})_{2}$ 为催化剂, 四甲基 胍为碱, $\mathrm{DMSO}$ 为溶剂实现了 $N$-(2-氨基苯基)吡唑导向 的 $\mathrm{C}_{\mathrm{Ar}}-\mathrm{H}$ 键的磺酰胺化反应. 该反应具有非常高的反 应效率，产率最高可达 $99 \%$, 反应条件相对温和, 但仍 然需要使用等物质的量的铜催化剂. 以外, 与上述吡啶 基和啞唑啉/酰胺基等导向基团相比, 该反应使用的导 向基团容易脱除和回收(Scheme 22).

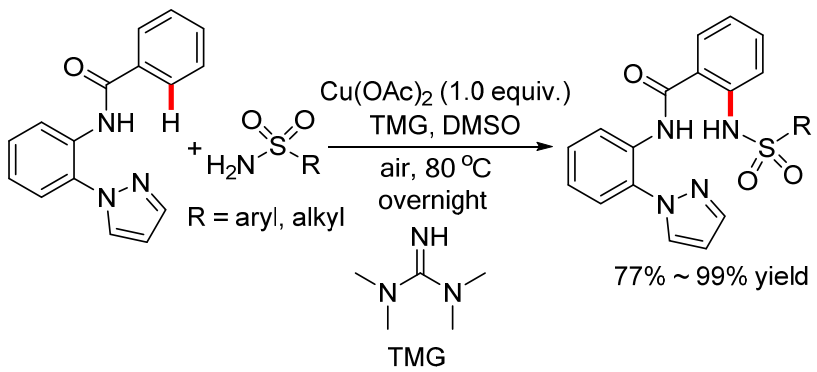

图式 22 铜催化 $N-\left(2\right.$ 氨基苯基)吡唑导向的 $\mathrm{C}_{\mathrm{Ar}}-\mathrm{H}$ 键的磺酰 胺化反应

Scheme 22 2-Aminophenyl-1H-pyrazole directed Coppermediated $\mathrm{C}_{\mathrm{Ar}}-\mathrm{H}$ sulfonamidation

2017 年崔冬梅课题组 ${ }^{[40]}$ 以醋酸铜为催化剂, 氧气 为氧化剂, 氯苯为溶剂, 实现了 2-氨基-4-( N, N-二甲基 氨基)-1,3,5-三嗪导向的芳环 $\mathrm{C}-\mathrm{H}$ 键的磺酰胺化反应. 该反应具有较好的底物普适性, 苯环上具有各种吸电子 和给电子基团的 6-芳基-2-氨基-4-( $N, N$-二甲基氨 基)-1,3,5-三嗪均能参与该反应，产率最高可达 $84 \%$ (Scheme 23).

\section{3 光诱导的 $\mathrm{C}_{\mathrm{Ar}}-\mathrm{H}$ 键氧化偶联反应}

光诱导的自由基反应具有绿色、高效的优点, 受到 了人们的广泛关注. 2016 年, König 课题组 ${ }^{[41]}$ 报道了光 诱导的吡咯衍生物的 2-位选择性 $\mathrm{C}-\mathrm{H}$ 键磺酰胺化反<smiles>[R][R]Oc1ccc(-c2nc(N)nc(N(C)O)n2)c([R])c1[R]</smiles>

$\mathrm{R}^{1}=\mathrm{H}, \mathrm{OMe} ; \mathrm{R}^{2}=\mathrm{H}, \mathrm{Me}$
$\mathrm{R}^{3}=\mathrm{H}, \mathrm{Me}, \mathrm{OMe}, \mathrm{Cl}, \mathrm{Br}$

图式 23 铜催化 2,4-二氨基-1,3,5-三嗪导向的 $\mathrm{C}_{\mathrm{Ar}}-\mathrm{H}$ 键的磺 酰胺化反应

Scheme 23 2,4-Diamino-1,3,5-triazine-directed Cu-catalyzed sulfonamidation of aromatic $\mathrm{C}-\mathrm{H}$ bonds

应. 该反应以商业可得的有机染料 $\mathbf{2 0}$ 为催化剂, $\mathrm{O}_{2}$ 为氧 化剂, $\mathrm{NaOH}$ 为碱，产率最高可达 $99 \%$. 反应机理如 Scheme 24 所示, 光氧化还原催化剂 20 获取光子能量后 生成激发态 $20 *$, 从 $N$-甲基吡咯上获取一个电子产生自 由基 20・和自由基正离子 21 . 中间体 $\mathbf{2 1}$ 与磺酰胺负离子 反应产生自由基 $\mathbf{2 2}$, 进一步被氧化后生成目标产物. 自 由基 20•被氧气氧化使光氧化还原催化剂再生.

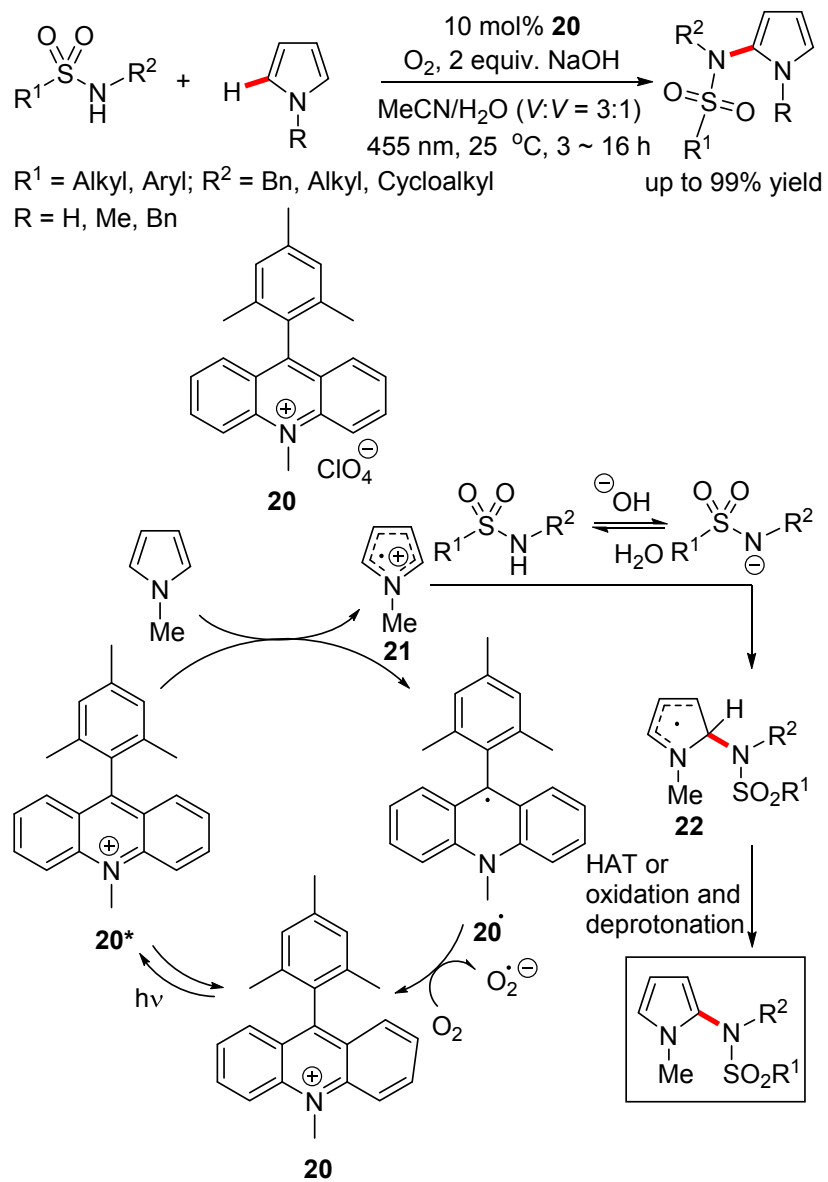

图式 24 光诱导的有机小分子催化的 $\mathrm{C}_{\mathrm{Ar}}-\mathrm{H}$ 键的磺酰胺化 反应

Scheme 24 Metal-free visible-light-induced C-H sulfonamidations of pyrroles 
同年, 张艳课题组 ${ }^{[42]}$ 用铱催化剂实现了光诱导的 吲哚衍生物的 2-位选择性磺酰胺化反应. 该反应以 $\operatorname{Ir}(\mathrm{ppy})_{2}(\mathrm{dtbbpy}) \mathrm{PF}_{6}$ 为光氧化还原催化剂, $\mathrm{NaClO}$ 为氧化 剂, 1,4-二氧六环为溶剂, 在室温下即可顺利进行, 产率 最高达 92\%. 其反应机理如 Scheme 25 所示, $\mathrm{Ir}^{\mathrm{III}}$ 在光的 激发下生成激发态的 $\mathrm{Ir}^{\mathrm{III}}$, 被 $\mathrm{NaClO}$ 氧化后生成 $\mathrm{Ir}^{\mathrm{IV}}$, 夺取并氧化 $N$-甲基磺酰胺上的氢原子生成自由基 $\mathbf{2 3}$, 同时使催化剂 $\mathrm{Ir}^{\mathrm{III}}$ 再生, 自由基 23 与 $N$-甲基吲哚发生自 由基加成反应生成自由基中间体 $\mathbf{2 4}$, 进一步被氧化后 产生碳正离子中间体 25, 脱去氢离子产生目标产物. 2017 年, 孙培培课题组 ${ }^{[43]}$ 利用类似的催化体系实现了 咪唑并吡啶衍生物的 3-位选择性 $\mathrm{C}-\mathrm{H}$ 键磺酰胺化反 应, 与上述光诱导的 $\mathrm{C}_{\mathrm{Ar}}-\mathrm{H}$ 磺酰胺化反应类似, 该反应 具有反应条件温和、反应效率高、底物适用范围广等优 点, 为 3-磺酰胺咪唑并吡啶类化合物的合成提供了一种 高效的合成方法.
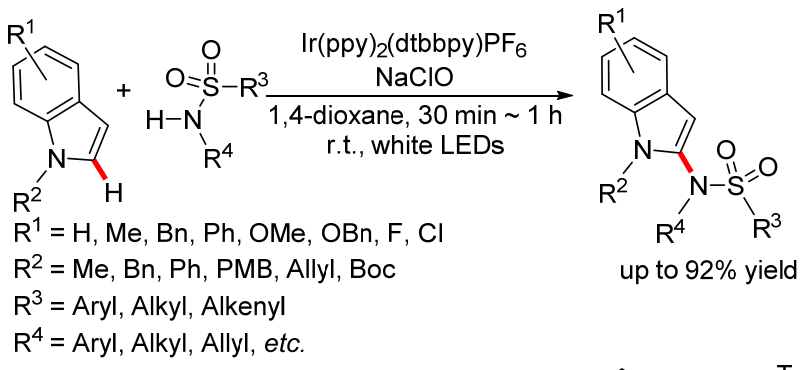

$\mathrm{R}^{4}=$ Aryl, Alkyl, Allyl, etc

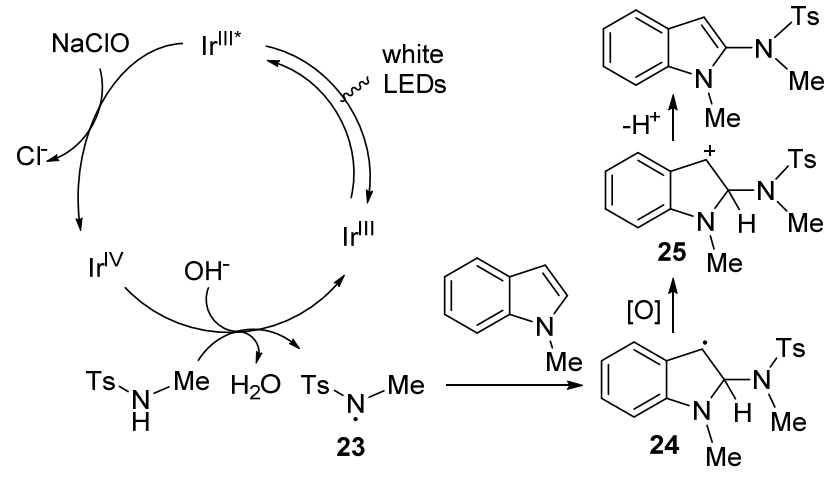

图式 25 光诱导的吲哚衍生物选择性的 $\mathrm{C}_{\mathrm{Ar}}-\mathrm{H}$ 键氧化磺酰 胺化反应

Scheme 25 Visible-light-induced direct oxidative $\mathrm{C}-\mathrm{H}$ sulfonamidations of indoles with sulfonamides

\section{4 过渡金属催化的 $\mathrm{C}_{\mathrm{Ar}}-\mathrm{H}$ 键氮宾插入反应}

氮宾是具有 6 个价电子的电中性活泼中间体, 为一 缺电子物种, 与卡宾具有类似的反应性, 都具有三线态 和单线态. 早期文献中所报道的氮宾为自由氮宾, 反应 活性很高, 因此其选择性相对较差, 反应产率较低. 1967 年, Kwart 和 $\mathrm{Kahn}^{[44]}$ 首次报道了过渡金属催化的氮 宾反应, 为 $\mathrm{C}-\mathrm{N}$ 键的构建提供了一种新的方法. 目前, 各类过渡金属催化的以磺酰亚胺碘苯 $\left(\mathrm{RSO}_{2} \mathrm{~N}=\mathrm{IPh}\right) 、$ 磺
酰叠氮等为氮宾前体的 $\mathrm{C}_{\mathrm{Ar}}-\mathrm{H}$ 键插入反应被相继报道, 为 $N$-芳基磺酰胺类化合物的合成提供了一类新颖、高 效、绿色的方法.

\section{1 以磺酰亚胺碘苯 $\left(\mathrm{RSO}_{2} \mathrm{~N}=\mathrm{IPh}\right)$ 为氮宾前体的} $\mathrm{C}_{\mathrm{Ar}}-\mathrm{H}$ 键插入反应

磺酰亚胺碘苯 $\left(\mathrm{RSO}_{2} \mathrm{~N}=\mathrm{IPh}\right)$ 是一类高活性氮宾前 体, 被广泛运用于 $\mathrm{C}-\mathrm{H}$ 键的磺酰胺化、 $\mathrm{C}=\mathrm{C}$ 键的氮杂 环丙烷化等反应. 2003 年, Pérez 课题组 ${ }^{[45]}$ 发现在催化量 的 $\mathrm{Tp}^{\mathrm{Br} 3} \mathrm{Cu}(\mathrm{NCMe})$ 存在下, 对甲苯磺酰亚胺碘苯与苯在 常温下即可顺利进行反应，产物组成为 $60 \% \mathrm{TsNH}_{2}$ 和 $40 \%$ PhNHTs (Scheme 26).

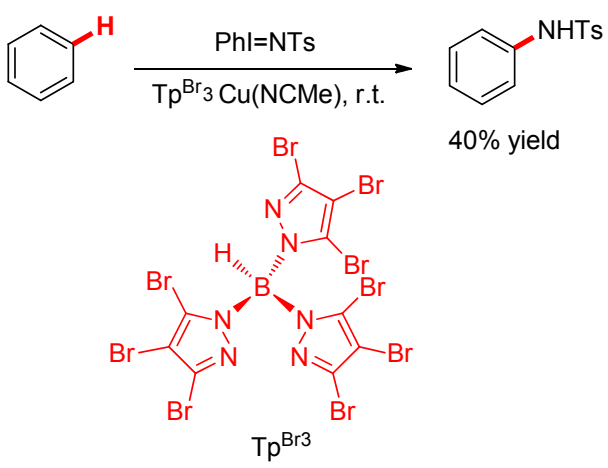

图式 $26 \mathrm{Tp}^{\mathrm{Br} 3} \mathrm{Cu}(\mathrm{NCMe})$ 催化的芳环 $\mathrm{C}-\mathrm{H}$ 键氮宾插入反应 Scheme $26 \mathrm{Tp}^{\mathrm{Br} 3} \mathrm{Cu}(\mathrm{NCMe})$ catalyzed nitrene insertions into $\mathrm{C}-\mathrm{H}$ bonds

2004 年, Sadighi 课题组 ${ }^{[46]}$ 以 $\mathrm{Cu}(\mathrm{I}) / 2,9$-二芳基-1,10菲啰啉络合物为催化剂, 对甲苯磺酰亚胺碘苯为氮宾前 体，实现了 1,3-二甲氧基苯的选择性芳环 $\mathrm{C}-\mathrm{H}$ 键氮宾 插入反应。该反应能在室温下进行，产率达到 $63 \%$ ，但 作者未对底物普适性进行研究(Scheme 27).

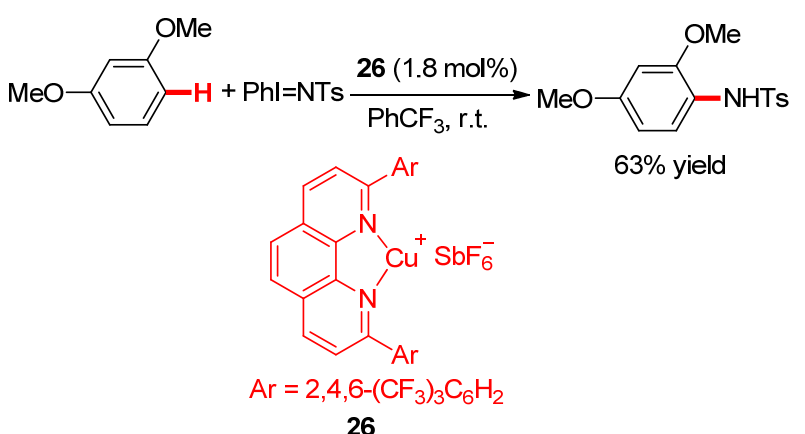

图 27 铜/菲啰啉类络合物催化的芳环 $\mathrm{C}-\mathrm{H}$ 键氮宾插入反应 Scheme 27 Copper/phenanthroline complex-catalyzed nitrene insertions into $\mathrm{C}-\mathrm{H}$ bonds

同年, 支志明课题组 ${ }^{[47]}$ 以钉/卟啉络合物 $\mathrm{Ru}^{\mathrm{II}}(\mathrm{TTP})-$ (CO)为催化剂实现了以磺酰亚胺碘苯为氮宾前体的吡 咯、呋喃、噻吩的 $\mathrm{C}-\mathrm{H}$ 键选择性磺酰胺化反应，产率 
最高可达 $84 \%$. 该反应有较好的底物普适性, 底物为呋 喃、噻吩、苯并呋喃、吲哚及 $N$-对甲苯磺酰吡咯时, 主 要得到一磺酰胺化产物, 而 $N$-烷基或芳基吡咯主要得 到 3,4-二磺酰胺化产物(Scheme 28).

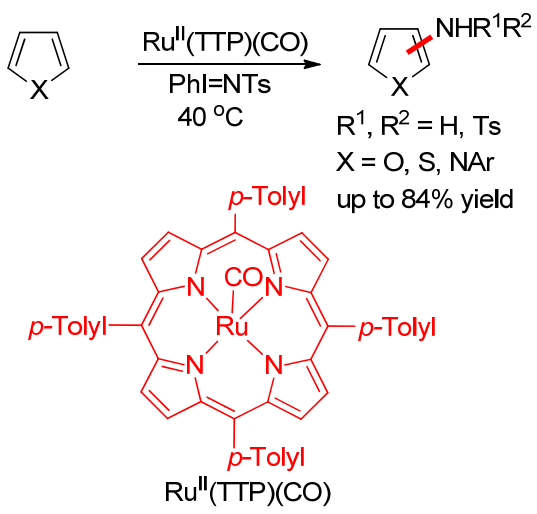

图式 28 钉催化的吡咯、呋喃、噻吩的 $\mathrm{C}-\mathrm{H}$ 键氮宾插入反 应

Scheme 28 Ruthenium(II) porphyrin-catalyzed sulfonamidation of aromatic heterocycles

由于苄位 $\mathrm{C}-\mathrm{H}$ 具有较强的活性, 过渡金属催化的 甲苯及其衍生物的 $\mathrm{C}-\mathrm{H}$ 键氮宾插入反应一般优先在苄 位上发生, 而芳环 $\mathrm{C}$ - $\mathrm{H}$ 键选择性氮宾插入反应一直较 难实现 ${ }^{[45,48]} .2007$ 年, $\mathrm{He}$ 课题组 ${ }^{[49]}$ 以 $\mathrm{AuCl}_{3}$ 为催化剂, $\mathrm{PhI}=\mathrm{NNs}$ 为氮宾前体, 突破性地实现了均三甲苯的高 选择性芳环 $\mathrm{C}-\mathrm{H}$ 键氮宾插入反应, 产率达到 $90 \%$. 其 反应机理如 Scheme 29 所示, 均三甲苯与 $\mathrm{AuCl}_{3}$ 络合生 成芳基金(III)络合物 27 , 接着与 $\mathrm{PhI}=\mathrm{NNs}$ 络合产生中 间体 28, 最后在氢离子辅助下生成目标产物.

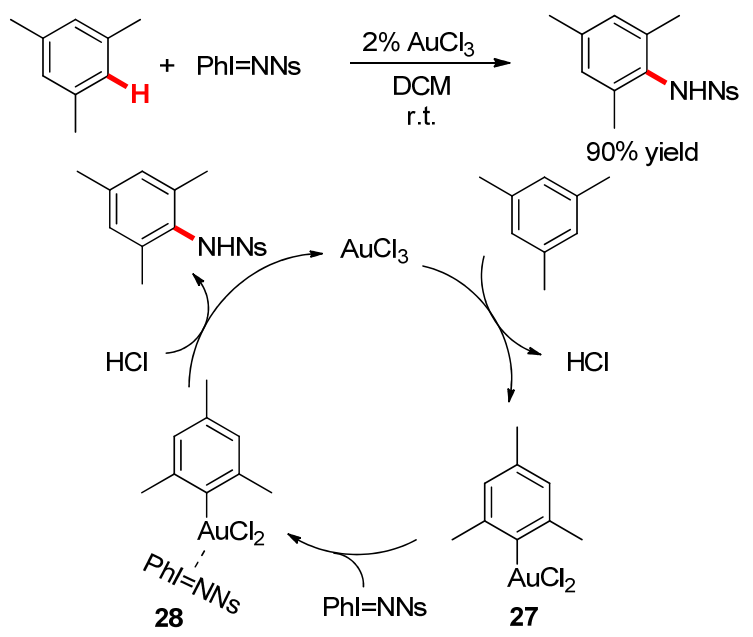

图式 29 金催化的芳环 $\mathrm{C}-\mathrm{H}$ 键高选择性氮宾插入反应 Scheme 29 Gold(III)-catalyzed nitrene insertion into aromatic $\mathrm{C}-\mathrm{H}$ bonds

2013 年, 苏伟平课题组 ${ }^{[50]}$ 利用 $\left[\mathrm{Cp}^{*} \mathrm{RhCl}_{2}\right]_{2} / \mathrm{AgSbF}_{6}$ 催化体系, 以 $\mathrm{PhI}(\mathrm{OAc})_{2}$ 与磺酰胺反应原位产生的磺酰
亚胺碘苯为氮宾前体，以 1,2 -二氯乙烷为反应溶剂，高 产率地实现了吡啶基、吡唑基等含氮官能团导向的芳环 $\mathrm{C}-\mathrm{H}$ 键磺酰胺化反应. 该反应条件温和, 底物适用范 围广泛，芳环上具有甲基、甲氧基、卤原子、醛基、硝 基等基团的反应底物均能顺利地实现邻位选择性 $\mathrm{C}-\mathrm{H}$ 键磺酰胺化, 芳香磺酰胺和脂肪磺酰胺均可作为磺酰胺 化试剂. 2017 年, 李洪基课题组 ${ }^{[51]}$ 以相同的反应体系实 现了氧化偶氮基为导向基团的芳环 $\mathrm{C}-\mathrm{H}$ 键的磺胺化反 应(Scheme 30).

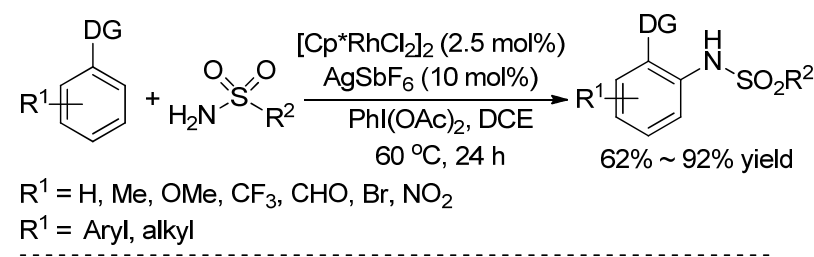<smiles>[3H]Nc1ccccc1-c1ccccn1</smiles>

$76 \%$<smiles>[AsH3-]Nc1cccc2ccc3cccnc3c12</smiles>

$91 \%$
$74 \%$<smiles>[AsH3]Nc1ccccc1-n1cccn1</smiles>

$62 \%$<smiles>Cc1ccc(-c2ccccc2NC(F)(F)F)nc1</smiles><smiles>O=C(Nc1ccccc1-c1ccc(F)cn1)c1ccccc1</smiles>

$71 \%$<smiles>[AsH3-]Nc1ccccc1-c1nccc2ccccc12</smiles>
$70 \%$<smiles>[3H]Nc1ccccc1C1=NC(C)CO1</smiles>

$80 \%$
图式 30 以磺酰胺为氮源的铑(III)催化含氮官能团导向的芳 环 $\mathrm{C}$ - $\mathrm{H}$ 键磺酰胺化反应

Scheme 30 Rhodium(III)-catalyzed $N$-chelator-directed aromatic $\mathrm{C}-\mathrm{H}$ sulfonamidation with sulfonamides

2019 年, 孙松课题组 ${ }^{[52]}$ 采用 $\left[\mathrm{Cp}^{*} \mathrm{RhCl}_{2}\right]_{2} / \mathrm{AgOTf} /$ $\mathrm{AgOAc} / \mathrm{HOAc}$ 催化体系, 以原位生成的磺酰亚胺碘苯 为磺酰胺化试剂, 高产率地实现了 $N$-酰基吲哚啉类化 合物的 7-位选择性 $\mathrm{C}-\mathrm{H}$ 键磺酰胺化反应. 该反应具有 较广的底物适用范围，苯环上有各类吸电子或给电子基 才的 $N$-酰基吲哚啉类化合物均适用于该反应，但当苯 环上有给电子基时产率较高(Scheme 31).

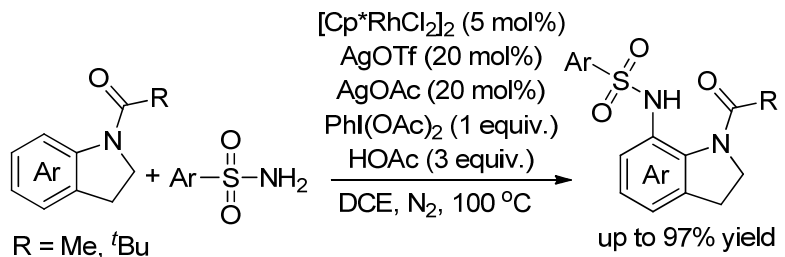

图式 31 铑(III)催化吲哚啉衍生物的 7-位选择性 C-H 键磺酰 胺化反应

Scheme 31 Rhodium(III)-catalyzed direct C-7 sulfonamidation of indolines with arylsulfonamides 


\section{2 以磺酰叠氮 $\left(\mathrm{RSO}_{2} \mathrm{~N}_{3}\right)$ 为氮宾前体的 $\mathrm{C}_{\mathrm{Ar}}-\mathrm{H}$ 键插 入反应}

磺酰叠氮是一类活性较高的氮宾前体, 以磺酰叠氮 为 $\mathrm{N}$ 源的氮宾转移反应往往显示出反应条件温和、反应 体系绿色、后处理简单等优点 (副产物为 $\mathrm{N}_{2}$ ), 因此, 磺 酰叠氮参与的 $\mathrm{C}-\mathrm{N}$ 键构建反应成为有机合成方法学研 究领域的热点 ${ }^{[53]}$.

\subsection{1 铑(III) 催化}

2012 年, Chang 课题组 ${ }^{[54]}$ 报道了以磺酰叠氮为氮宾 前体的 2-芳基吡啶的 $\mathrm{C}_{\mathrm{Ar}}-\mathrm{H}$ 键插入反应. 该反应以 $\left[\mathrm{RhCp}^{*} \mathrm{Cl}_{2}\right]_{2}$ 为铑源, $\mathrm{AgSbF}_{6}$ 为添加剂, 1,2 -二氯乙烷为 溶剂, 具有反应条件温和, 反应体系绿色环保, 反应效 率高, 底物适应范围广等优点. 反应机理如 Scheme 32 所示, 二聚铑络合物 $\left[\mathrm{RhCp}^{*} \mathrm{Cl}_{2}\right]_{2}$ 与 $\mathrm{AgSbF}_{6}$ 反应生成单 核铑络合物 $\left[\mathrm{RhCp}^{*}\right]\left(\mathrm{SbF}_{6}\right)_{2}$, 接着与 2-芳基吡啶络合产 生铑环络合物 29, 进而与 $\mathrm{RSO}_{2} \mathrm{~N}_{3}$ 络合生成中间体 $\mathbf{3 0}$, 脱氮气后生成铑氮宾中间体 31 , 接着氮宾插入 $\mathrm{C}-\mathrm{Rh}$ 键生成中间体 32 , 最后中间体 32 在另一分子底物的金 属化/脱质子化的促进下发生质子化/脱金属化反应重新
生成中间体 29 并得到目标产物 ${ }^{[55]}$.

随后各类含氮官能团导向的以磺酰叠氮为氮源的 铑催化芳环和杂芳环 $\mathrm{C}-\mathrm{H}$ 键磺酰胺化反应被相继报 道. 2012 年, 周兵课题组 ${ }^{[56]}$ 报道了以磺酰叠氮为氮宾前 体的、嘧啶基导向的吲哚环选择性 2-位 C- $\mathrm{H}$ 键的磺酰 胺化反应. 该反应以 $\left[\mathrm{Cp}^{*} \mathrm{Rh}\left(\mathrm{CH}_{3} \mathrm{CN}\right)_{3}\right]\left(\mathrm{SbF}_{6}\right)_{2}$ 为铑源, 1,2-二氯乙烷为溶剂, 具有反应条件温和, 底物普适性 强的优点, 为 2-磺酰氨基吲哚类化合物的合成提供了一 种有效的方法(Scheme 33).

2013 年, Glorius 课题组 ${ }^{[57]}$ 通过 $\mathrm{Rh}^{\mathrm{III}} / \mathrm{Cu}^{\mathrm{II}}$ 共催化的方 法, 实现了芳基亚氨酸酯的芳环 $\mathrm{C}-\mathrm{H}$ 键磺酰胺化/ $\mathrm{N}-\mathrm{N}$ 氧化关环串联反应，为 1-磺酰基-3-烃氧基吲唑类 化合物的合成提供了一种高效、绿色、通用的合成方法. 该反应的反应机理包括铑、铜两个催化循环. 如 Scheme 34 所示, $\left[\mathrm{Cp}^{*} \mathrm{RhCl}_{2}\right]_{2}$ 与 $\mathrm{AgSbF}_{6}$ 反应生成的单核铑配合 物 $\left[\mathrm{Cp}^{*} \mathrm{Rh}^{\mathrm{III}}\right]\left(\mathrm{SbF}_{6}\right)_{2}$ 与芳基亚氨酸酯络合产生铑环中间 体 33, 进一步与 $\mathrm{TsN}_{3}$ 络合产生中间体 34, 释放出一分 子氮气生成六元铑环中间体 35 , 进一步发生质子化/脱 金属化反应得到中间产物 36 和催化剂 $\left[\mathrm{Cp}^{*} \mathrm{Rh}^{\mathrm{III}}\right]\left(\mathrm{SbF}_{6}\right)_{2}$,

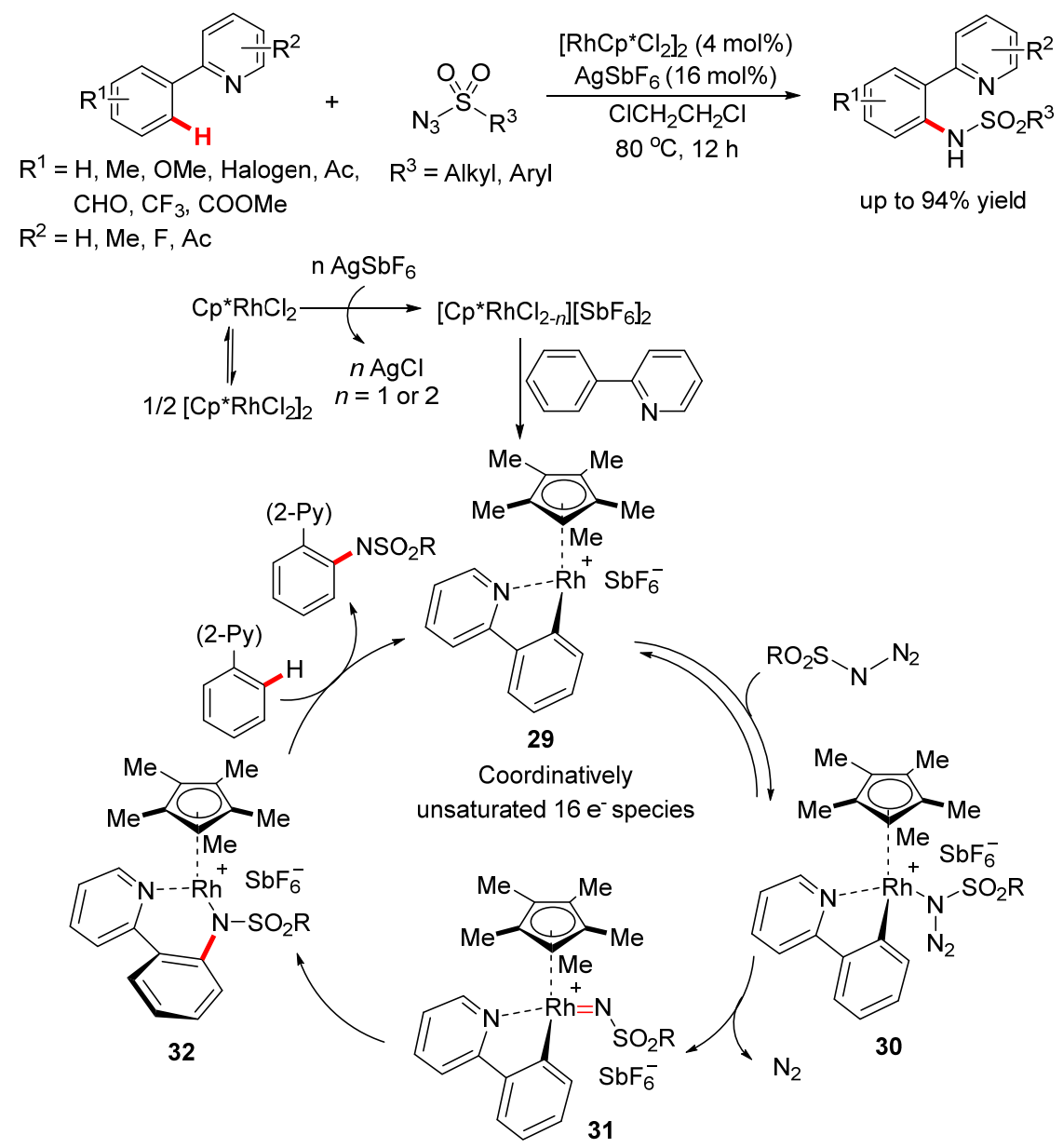

图式 32 铑催化的以磺酰叠氮为氮源的 $\mathrm{C}_{\mathrm{Ar}}-\mathrm{H}$ 键插入反应

Scheme 32 Rhodium-catalyzed sulfonamidation of arenes with sulfonyl azides 

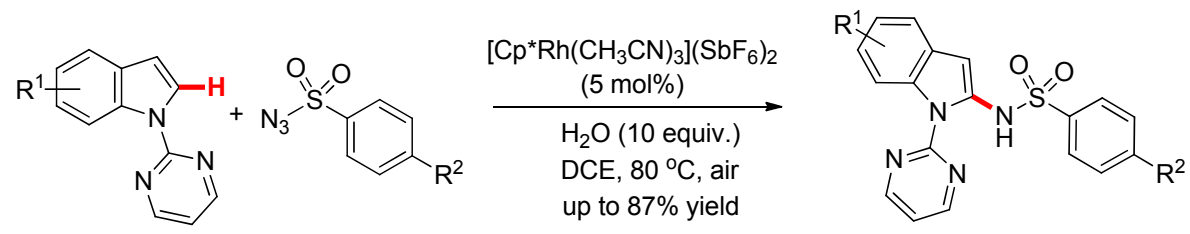

$\mathrm{R}^{1}=\mathrm{H}, \mathrm{Me}, \mathrm{OMe}, \mathrm{CF}_{3}, \mathrm{COOMe}, \mathrm{NO}_{2}$, Halogen

$\mathrm{R}^{2}=\mathrm{H}, \mathrm{NO}_{2}$, OMe

图式 33 铑催化嘧啶基导向的 $\mathrm{C}_{\mathrm{Ar}}-\mathrm{H}$ 键氮宾插入反应

Scheme 33 Rhodium-catalyzed regioselective sulfonamidation of indoles with sulfonyl azides<smiles>[R]OC(=N)c1cc#[R]cc1</smiles>

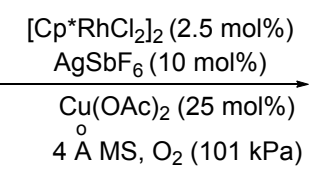
DCE, $110^{\circ} \mathrm{C}, 24 \mathrm{~h}$

$\mathrm{R}=\mathrm{H}$, Halogen, $\mathrm{CF}_{3}$, OPh, OEt, $\mathrm{CO}_{2} \mathrm{Et}$, etc.; $\mathrm{R}^{1}=\mathrm{Me}, \mathrm{Et},{ }^{i} \mathrm{Pr} ; \mathrm{R}^{2}=\mathrm{Aryl}, \mathrm{Bn},{ }^{n} \mathrm{Bu}$

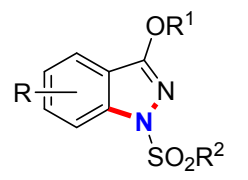
$46 \% \sim 79 \%$ yield
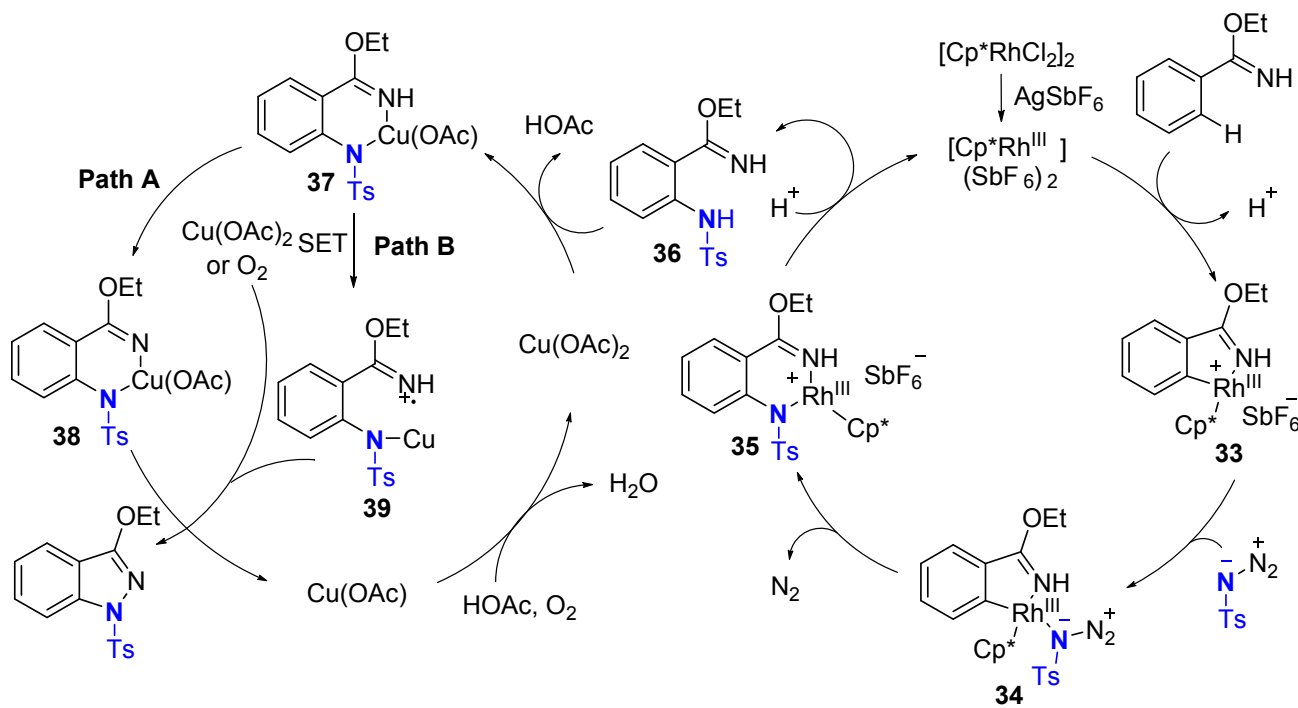

图式 $34 \mathrm{Rh}^{\mathrm{III}} / \mathrm{Cu}^{\mathrm{II}}$ 催化 $\mathrm{C}-\mathrm{H}$ 键磺酰胺化 $/ \mathrm{N}-\mathrm{N}$ 氧化关环串联反应

Scheme $34 \mathrm{Rh}^{\mathrm{III}} / \mathrm{Cu}^{\mathrm{II}}$-cocatalyzed synthesis of $1 \mathrm{H}$-Indazoles through $\mathrm{C}-\mathrm{H}$ sulfonamidation and $\mathrm{N}-\mathrm{N}$ bond formation

完成铑催化循环. 中间产物 36 与 $\mathrm{Cu}(\mathrm{OAc})_{2}$ 络合生成 $\mathrm{Cu}^{\mathrm{II}}$ 中间体 37, 被 $\mathrm{Cu}(\mathrm{OAc})_{2}$ 或 $\mathrm{O}_{2}$ 氧化生成 $\mathrm{Cu}^{\mathrm{III}}$ 中间体 38 , 还原消除生成产物和 $\mathrm{CuOAc}, \mathrm{CuOAc}$ 被 $\mathrm{O}_{2}$ 氧化成 $\mathrm{Cu}(\mathrm{OAc})_{2}$, 从而完成铜催化循环. 中间体 $\mathbf{3 7}$ 也可能通过 单电子转移(SET)机制 ${ }^{[58]}$ 产生自由基正离子 39, 进一步 氧化后关环生成目标产物和 CuOAc (Scheme 34).

2014 年, 许斌课题组 ${ }^{[59]}$ 报道了偶氮基导向的、以磺 酰叠氮为氮源的芳环 $\mathrm{C}-\mathrm{H}$ 键氮宾插入反应. 该反应以 [RhCp* $\left.\mathrm{Cl}_{2}\right]_{2}$ 为铑源, $\mathrm{AgSbF}_{6}$ 为添加剂, 1,2 -二氯乙烷为 溶剂, 产率最高可达 95\% (Scheme 35). 几乎同时, Jia 课 题组 ${ }^{[60]}$ 也报道了一例极为类似的反应, 不同之处是所 使用的添加剂为 $\mathrm{AgNTf}_{2}$.

2015 年, 彭以元课题组 ${ }^{[61]}$ 报道了以喹唑啉基为导 向基团、磺酰叠氮为氮源的铑催化芳环 $\mathrm{C}-\mathrm{H}$ 键氮宾插 入反应. 以 $\left[\mathrm{RhCp}^{*} \mathrm{Cl}_{2}\right]_{2}$ 为铑源, $\mathrm{AgSbF}_{6}$ 为添加剂, 1,2-

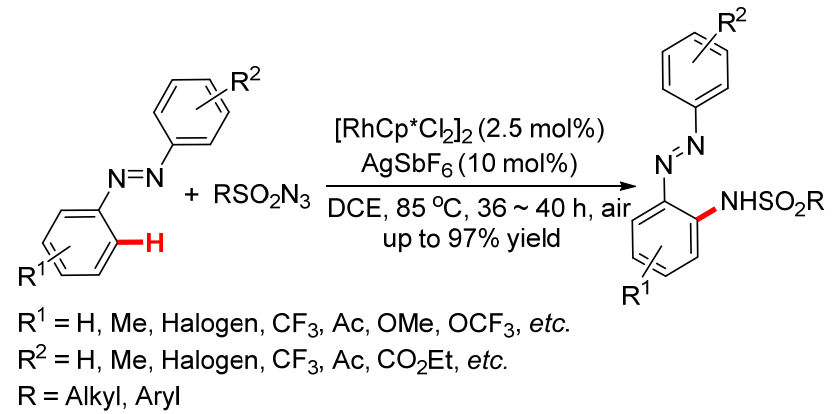

图式 35 偶氮基为导向基团的铑催化芳环 $\mathrm{C}-\mathrm{H}$ 氮宾插入反 应

Scheme 35 Rhodium-catalyzed regioselective sulfonamidation of azo compounds

二氯乙烷为溶剂, 磺酰胺化反应选择性地在 2,4-二芳基 喹啉的 2-位芳环上进行, 产率最高可达 95\% (Scheme 36). 


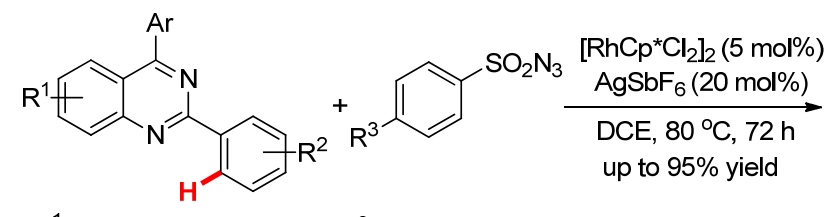

$\mathrm{R}^{1}=\mathrm{H}, \mathrm{F}, \mathrm{Ph}$

$\mathrm{R}^{2}=\mathrm{H}, \mathrm{F}, \mathrm{OMe}, \mathrm{Me}$ $\mathrm{R}^{3}=\mathrm{Me}, \mathrm{Cl}, \mathrm{NO}_{2}, \mathrm{OMe}$<smiles>[R]c1ccc(NS(=O)(=O)c2ccc([R])cc2)cc1</smiles>

图式 36 喹啉基导向的铑催化芳环 $\mathrm{C}-\mathrm{H}$ 氮宾插入反应 Scheme 36 Rhodium-catalyzed regioselective direct $\mathrm{C}-\mathrm{H}$ sulfonamidation of 2,4-diarylquinazolines with sulfonyl azides

\subsection{2 铱(III) 催化}

2013 年, Chang 课题组 ${ }^{[62]}$ 以磺酰叠氮为氮宾前体, 对铱催化的官能团导向的芳环 $\mathrm{C}-\mathrm{H}$ 键磺酰胺化反应进 行了系统的研究, 发现 $\left[\mathrm{IrCp}^{*} \mathrm{Cl}_{2}\right]_{2} / \mathrm{AgNTf}_{2}$ 催化体系能 有效地促进芳香酰胺、酰基芳胺、腙、肟、吡唑、吡啶、 啞唑啉、苯并噁唑、异喹啉等官能团导向的芳环 $\mathrm{C}-\mathrm{H}$ 键氮宾插入反应，产率最高可达 $96 \%$ (Scheme 37).

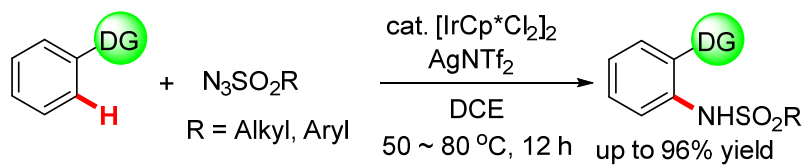
amides, anilides, hydrazones, oximes, heterocycles, carbamates

图式 37 铱催化以磺酰叠氮为氮源的芳环 $\mathrm{C}-\mathrm{H}$ 磺胺化反应 Scheme 37 Iridium-catalyzed direct arene $\mathrm{C}-\mathrm{H}$ bond sulfonamidation with sulfonyl azides

2014 年, 该课题组 ${ }^{[63]}$ 对上述铱催化的芳环 $\mathrm{C}-\mathrm{H}$ 键 磺酰胺化反应进行了深入的研究, 提出了 Scheme 38 所 示的反应机理. 首先, $N$-叔丁基苯甲酰胺与 $\left[\operatorname{Ir}^{\mathrm{III}} \mathrm{Cp}\right.$ *]$\left(\mathrm{NTf}_{2}\right)_{2}$ 络合产生五元铱环中间体 40, 接着与磺酰叠氮 络合产生中间体 41, 脱除一分子氮气产生铱氮宾 42, 氮 宾插入 $\mathrm{C}-\mathrm{Ir}$ 键产生六元铱环中间体 43 , 最后, 在中间 体 43 的质子化/脱金属化和另一分子 $N$-叔丁基苯甲酰胺 的脱质子化/金属化协同作用下，重新生成五元铱环中 间体 $\mathbf{4 0}$ 和目标产物.

随后各类官能团导向的、以磺酰叠氮为氮源的铱催 化芳环和杂芳环 C-H 键插入反应被相继报道. 2014 年, Chang 课题组 ${ }^{[64]}$ 报道了铱催化芳基次膦酸酯、次膦酰胺 以及芳基氧膦的芳环 $\mathrm{C}-\mathrm{H}$ 键氮宾插入反应. 该反应底 物适应范围广，反应条件温和，产率最高可达 $95 \%$ (Scheme 39).

喹啉骨架广泛存在于具有生物活性的分子中, 喹啉

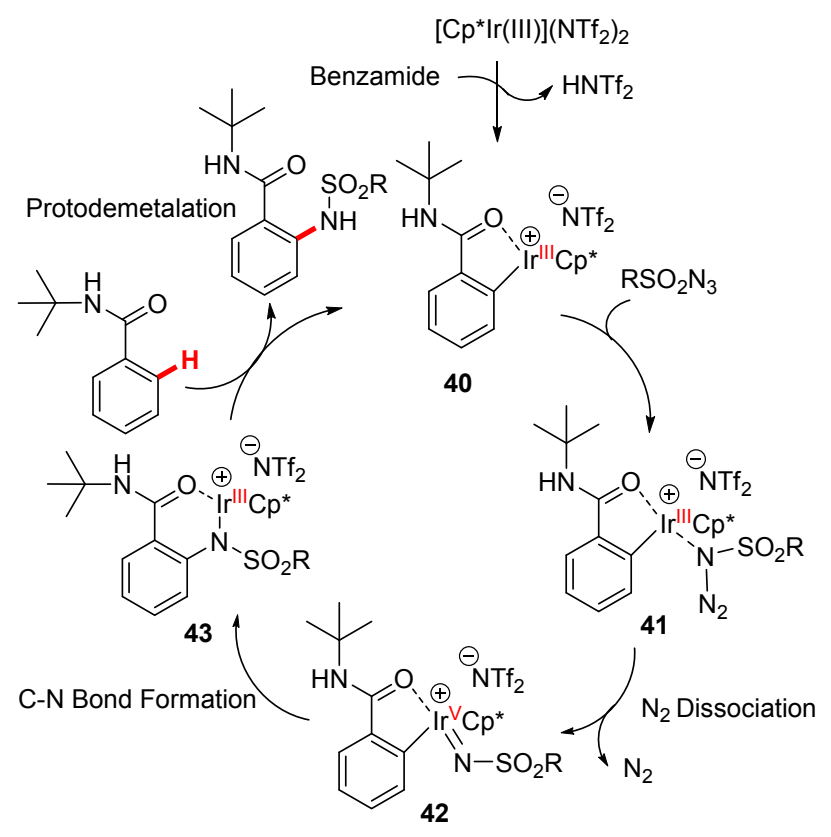

图式 38 铱催化以磺酰叠氮为氮源的芳环 $\mathrm{C}-\mathrm{H}$ 磺胺化反应 机理

Scheme 38 Mechanism of Iridium(III)-catalyzed $\mathrm{C}-\mathrm{H}$ sulfonamidations of benzamides with organic azides

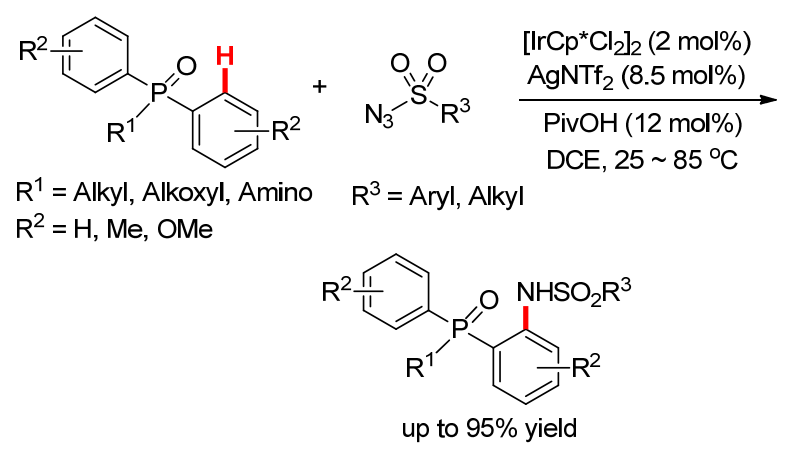

图式 39 铱催化芳基次膦酸酯等含磷化合物的芳环 $\mathrm{C}-\mathrm{H}$ 键 氮宾插入反应

Scheme 39 Iridium(III)-catalyzed $\mathrm{C}-\mathrm{H}$ sulfonamidation of arylphosphoryls

环上的选择性结构修饰对喹啉类药物的开发具有十分 重要的意义. 2014 年, Chang 课题组 ${ }^{[65]}$ 报道了铱催化的 喹啉氮氧的 8-位选择性 $\mathrm{C}-\mathrm{H}$ 键氮宾插入反应. 该反应 同样采用 $\left[\mathrm{IrCp}^{*} \mathrm{Cl}_{2}\right]_{2} / \mathrm{AgNTf}_{2}$ 催化体系, 但发现加入适 量的醋酸能大大的提高反应效率. 其反应机理如 Scheme 40 所示, 原位产生的催化剂 $\left[\mathrm{Cp}^{*} \mathrm{Ir}^{\mathrm{III}}\right]$ 与喹啉氮 氧络合产生五元铱环中间体 44 , 与磺酰叠氮络合生成 中间体 45, 脱氮气生成中间体 46, 在醋酸分子的协同 下，通过过渡态 47 进行质子化/脱金属反应生成中间体 48, 最后在氢离子的协助下重新生成催化剂 $\left[\mathrm{Cp}^{*} \mathrm{Ir}^{\mathrm{III}}\right]$, 同时得到目标产物. 


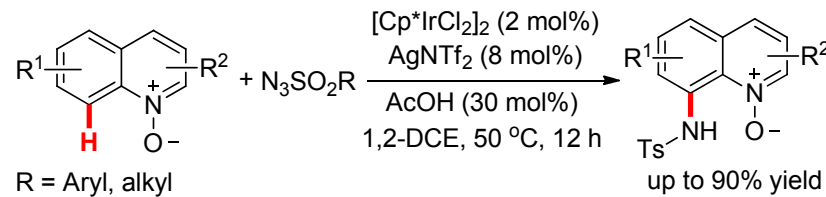

$\mathrm{R}^{1}=\mathrm{H}, \mathrm{CH}_{3}, \mathrm{Cl}, \mathrm{Br}, \mathrm{NO}_{2}, \mathrm{CO}_{2} \mathrm{Me}, \mathrm{OMe}, \mathrm{N}(\mathrm{Boc})_{2}, \mathrm{OSii}_{-} \mathrm{Pr}_{3}$, etc.

$\mathrm{R}^{2}=\mathrm{H}, \mathrm{Me}, \mathrm{Cl}, \mathrm{CHO}$, etc.

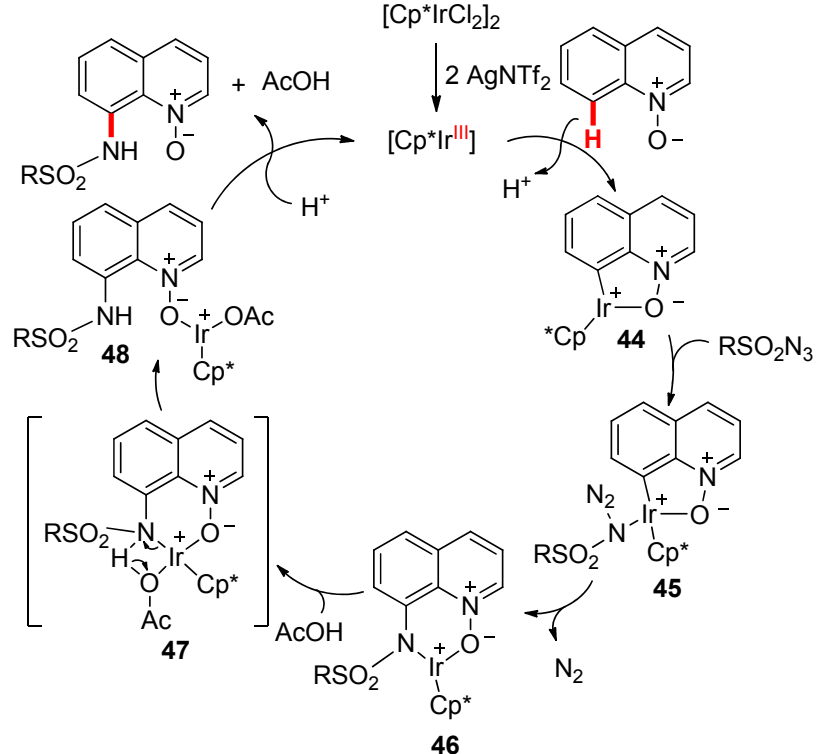

图式 40 铱催化喹啉氮氧的 8-位选择性 $\mathrm{C}-\mathrm{H}$ 键氮宾插入反 应

Scheme 40 Iridium(III)-catalyzed $\mathrm{C}-\mathrm{H}$ sulfonamidation at the $\mathrm{C}-8$ position of quinoline $N$-oxides

酯基的络合能力较弱, 以酯基为导向基团的 $\mathrm{C}_{\mathrm{Ar}}-$ $\mathrm{H}$ 键氮宾插入反应较难实现, 2014 年, Chang 课题组 ${ }^{[66]}$ 通过向 $\left[\mathrm{IrCp}^{*} \mathrm{Cl}_{2}\right]_{2} / \mathrm{AgNTf}_{2}$ 催化体系中加入添加剂 $\mathrm{AcOH} / \mathrm{Li}_{2} \mathrm{CO}_{3}$, 成功地突破了该反应, 产率最高可达 99\%. 此外, 该催化体系对酮羰基导向的 $\mathrm{C}_{\mathrm{Ar}}-\mathrm{H}$ 磺酰胺 化反应同样有效. 作者认为该反应的活性催化物种为 $\left[\mathrm{Ir}^{\mathrm{III}} \mathrm{Cp} * \mathrm{OAc}\right]$, 其与芳香羧酸酯的金属环化反应经历了 如 Scheme 41 所示的过渡态 49.

同年, Chang 课题组 ${ }^{[67]}$ 发现 $\left[\mathrm{IrCp}^{*} \mathrm{Cl}_{2}\right]_{2} / \mathrm{AgNTf}_{2}$ 催化 体系同样适用于乙酰基、叔丁氧羰基、茮氧羰基等导向 的吲哚啉 7-位 $\mathrm{C}-\mathrm{H}$ 键磺胺化反应. 该课题组的研究表 明, 醋酸钠能有效的促进该反应, 使 $\mathrm{AgNTf}_{2}$ 的用量大 大降低, 且在室温下就能顺利进行(Scheme 42). 几乎同 时, $\mathrm{Li}$ 课题组 ${ }^{[68]}$ 也报道了一例类似的反应.

2015 年, Chang 课题组 ${ }^{[69]}$ 采用 $\left[\mathrm{IrCp}^{*} \mathrm{Cl}_{2}\right]_{2} / \mathrm{AgNTf}_{2}$ 催 化体系实现了羧基导向的邻位 $\mathrm{C}-\mathrm{H}$ 键磺胺化反应, 作 者发现, 向反应体系中添加 LiOAc 能大大提高反应效 率，各类芳基甲酸以及 $\alpha, \beta$-不饱和羧酸均适合该反应体 系, 产率最高可达 $89 \%$. 作者进一步研究发现, 在 15 $\mathrm{mol} \% \mathrm{Pd}(\mathrm{OAc})_{2}$ 催化下, 磺酰胺化产物 $\mathbf{5 0}$ 能进一步发生 脱羧反应生成 $N$-芳基磺酰胺类化合物 $\mathbf{5 1}$, 并且脱羒催

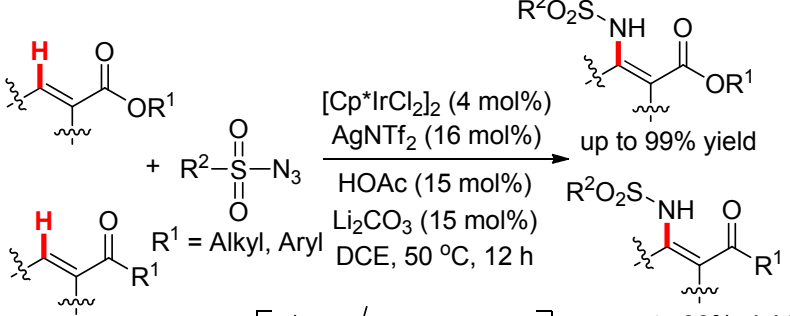

$\mathrm{R}^{1}=$ Alkyl, Alkenyl

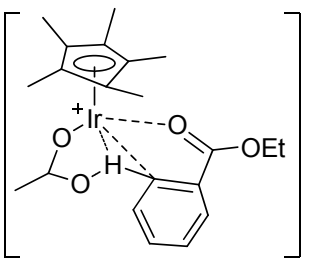

up to $99 \%$ yield

图式 41 铱催化羧酸酯基和酮羰基导向的 $\mathrm{C}_{\mathrm{sp}^{2}}-\mathrm{H}$ 键磺酰胺 化

Scheme 41 Iridium-catalyzed sulfonamidation of ester and ketone derivatives

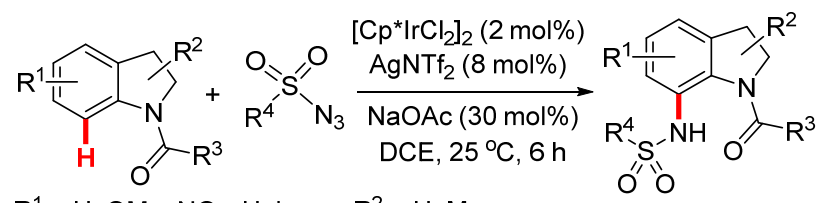

$\mathrm{R}^{1}=\mathrm{H}, \mathrm{OMe}, \mathrm{NO}_{2}$, Halogen; $\mathrm{R}^{2}=\mathrm{H}, \mathrm{Me}$

$\mathrm{R}^{3}=\mathrm{Me}, \mathrm{Ot}-\mathrm{Bu} . \mathrm{OCH}_{2} \mathrm{Ph} \mathrm{NEt}_{2} ; \mathrm{R}^{4}=$ Aryl, Alkyl

up to $98 \%$ yield

图式 42 铱催化吲哚啉 7-位 $\mathrm{C}-\mathrm{H}$ 键磺胺化反应

Scheme 42 Iridium(III)-catalyzed direct C-7 sulfonamidation of indolines

化体系和磺酰胺化体系是兼容的, 可实现一锅法操作, 从而为芳环上定点引入磺酰氨基提供了简便的新方法.

一锅法反应的产率最高可达 $89 \%$ (Scheme 43).

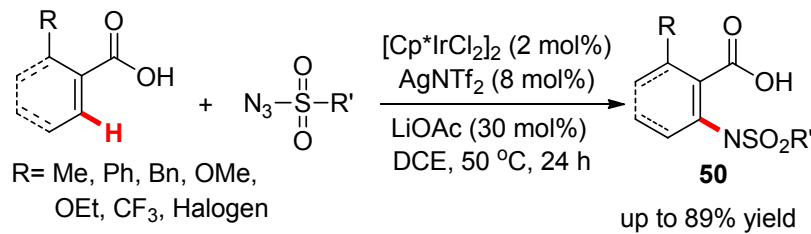
$\mathrm{R}^{\prime}=$ Aryl, Alkyl

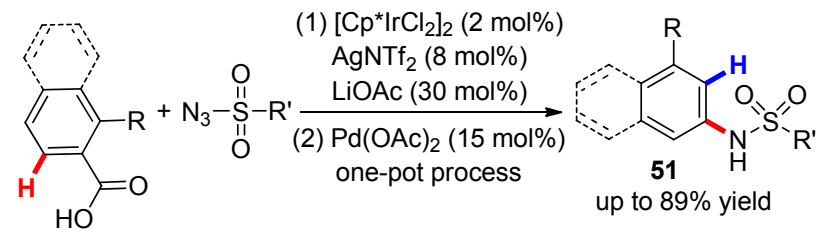

$\mathrm{R}=\mathrm{Me}, \mathrm{Ph}, \mathrm{OMe}, \mathrm{On}-\mathrm{Pr}, \mathrm{OEt}, \mathrm{CF}_{3}$, Halogen

$\mathrm{R}^{\prime}=$ Aryl, Alkyl

图式 43 铱催化苯甲酸衍生物的 $\mathrm{C}-\mathrm{H}$ 键磺酰胺化反应

Scheme 43 Iridium(III)-catalyzed direct $\mathrm{C}-\mathrm{H}$ sulfonamidation of benzoic acids

同年，崔秀灵课题组 ${ }^{[70]}$ 报道了铱催化 $N$-叔丁基- $\alpha$ 芳基硝酮的 $\mathrm{C}-\mathrm{H}$ 键磺酰胺化反应. 在 $\left[\mathrm{IrCp}^{*} \mathrm{Cl}_{2}\right]_{2} /$ $\mathrm{AgNTf}_{2}$ 体系催化下，亚胺氮氧基导向的芳环邻位 $\mathrm{C}-\mathrm{H}$ 
键氮宾插入反应能在常温下顺利进行, 对大多数底物产 率能达到 $90 \%$ 以上，各类吸电子和给电子基团取代的 $N$-叔丁基- $\alpha$-芳基硝酮及芳基、烷基磺酰叠氮均适用于该 反应体系(Scheme 44).

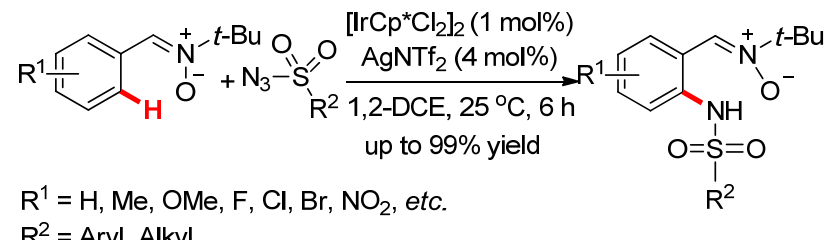

$\mathrm{R}^{2}=$ Aryl, Alkyl

图式 44 铱催化 $N$-叔丁基- $\alpha$-芳基硝酮的 $\mathrm{C}-\mathrm{H}$ 键磺酰胺化反 应

Scheme 44 Iridium-catalyzed direct $\mathrm{C}-\mathrm{H}$ sulfonamidation of aryl nitrones with sulfonyl azides

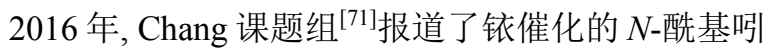
哚的 7-位选择性 $\mathrm{C}-\mathrm{H}$ 键磺酰胺化反应. 在不加任何添 加剂的情况下, $\operatorname{IrCp}^{*}(\mathrm{OAc})_{2} / \mathrm{AgNTf}_{2}$ 体系能高效地催化 $N$-酰基吲哚类化合物的 7-位 $\mathrm{C}-\mathrm{H}$ 键选择性磺酰胺化, 反应在室温下进行, 产率最高达 $99 \%$. 各类官能团取代 的吲哚底物均适合该反应, $\mathrm{R}^{3}$ 为大位阻烷基时, 反应的 产率较高, $\mathrm{R}^{3}$ 为小位阻烷基或芳基时, 产率较低. 在不 添加任何添加剂的情况下, 经典的 $\left[\mathrm{IrCp}^{*} \mathrm{Cl}_{2}\right]_{2} / \mathrm{AgNTf}_{2}$ 体系不能催化该反应, 但在 $\mathrm{AgOAc} c^{[72]}$ 或 $\mathrm{LiOAc}^{[73]}$ 为添 加剂及加热的条件下, $\left[\mathrm{IrCp}^{*} \mathrm{Cl}_{2}\right]_{2} / \mathrm{AgNTf}_{2}$ 体系也能高效 地催化该反应(Scheme 45).

\section{Chang's work:}

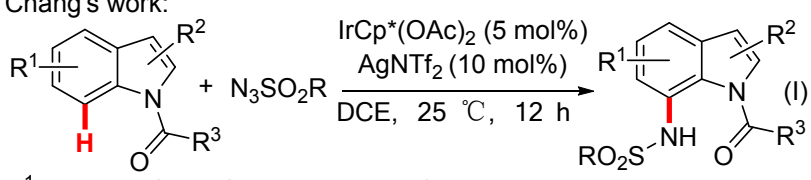

$\mathrm{R}^{1}=\mathrm{H}, \mathrm{Me}, \mathrm{OMe}, \mathrm{OBn}$, Halogen, $\mathrm{NO}_{2}$, etc.

$\mathrm{R}^{2}=\mathrm{H}, \mathrm{Me}, \mathrm{Cl}, \mathrm{Ac}$

$\mathrm{R}^{3}=$ Alkyl, Cycloalkyl; $R=$ Aryl, Alkyl
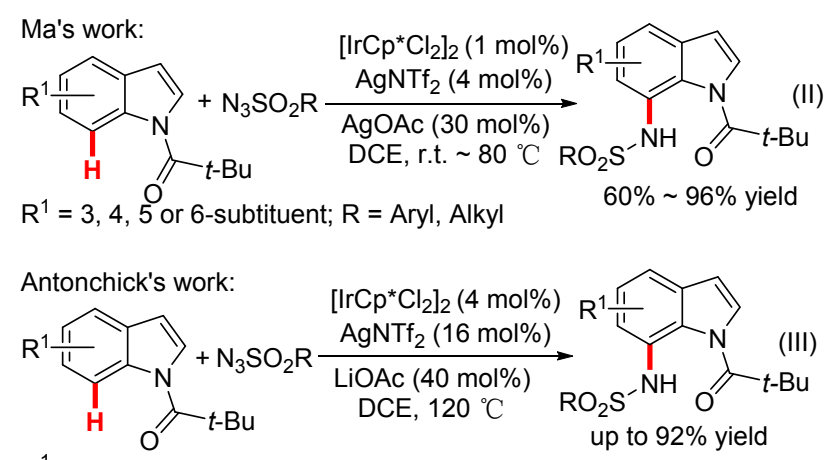

$\mathrm{R}^{1}=3,4,5$ or 6 -subtituent; $\mathrm{R}=$ Aryl, Alkyl

图式 45 铱催化 $N$-酰基吲哚的 7-位选择性 $\mathrm{C}-\mathrm{H}$ 键磺酰胺化 反应

Scheme 45 Iridium-catalyzed direct C-7 sulfonamidation of $\mathrm{N}$ acylindoles with sulfonyl azides

2016 年, 崔秀灵课题组 ${ }^{[74]}$ 和施章杰课题组 ${ }^{[75]}$ 几乎
同时报道了铱催化的亚胺类基团导向的芳环 $\mathrm{C}-\mathrm{H}$ 键磺 胺化反应. 前者以磺酰亚胺为导向基团，采用 $[\mathrm{IrCp} *$ $\left.\mathrm{Cl}_{2}\right]_{2} / \mathrm{AgNTf}_{2}$ 催化体系, 产物水解后生成邻磺酰氨基芳 香醛，产率最高达 95\%. 后者以 $N$-芳基亚胺为导向基 才, $\left[\mathrm{Cp}^{*} \mathrm{IrCl}_{2}\right]_{2} / \mathrm{AgPF}_{6}$ 为催化剂, 产率最高可达 $96 \%$, 各 类吸电子和给电子基团取代的芳香醛的亚胺均能参与 该反应. 芳香醛与 3-三氟甲基苯胺原位产生的亚胺也适 用该反应体系，且只用催化量的 3-三氟甲基苯胺就能以 最高 $84 \%$ 的产率得到 2-磺酰氨基芳香醛(Scheme 46). 2017 年, 陈弓课题组 ${ }^{[76]}$ 采用 $\left[\mathrm{IrCp}^{*} \mathrm{Cl}_{2}\right]_{2} / \mathrm{AgNTf}_{2}$ 催化体 系, 以 3,5-双(三氟甲基)苯胺为亚胺化试剂(用量降低至 $10 \mathrm{~mol} \%$ ), 使芳香醛的 2-位磺酰胺化产率大大提高, 最 高可达 98\%.

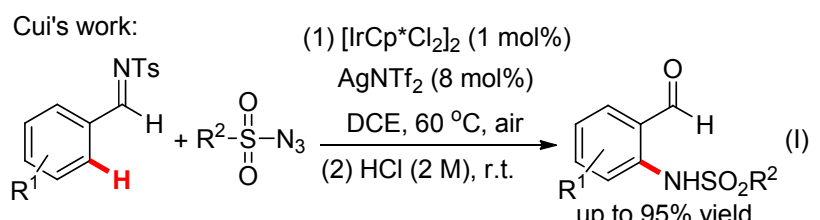
$\mathrm{R}^{1}=\mathrm{H}, \mathrm{Me}$, Halogen, OMe, CF3, etc.; $\mathrm{R}^{2}=$ Aryl, Alkyl

Shi's work:

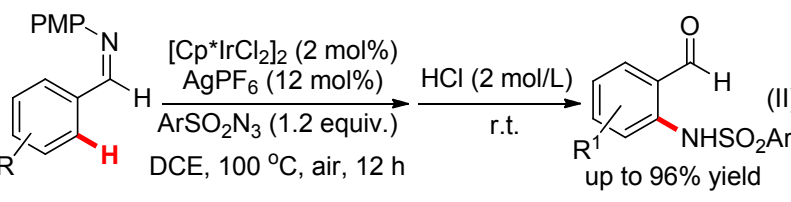

$\mathrm{PMP}=4$-methoxyphenyl

$\mathrm{R}=\mathrm{H}$, Halogen, $\mathrm{NO}_{2}, \mathrm{CF}_{3}, \mathrm{Me}, \mathrm{CO}_{2} \mathrm{Me}, \mathrm{CN}$, OMe, etc

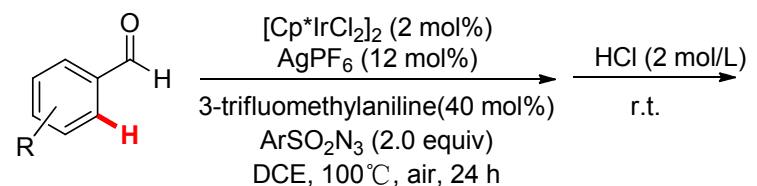

$\mathrm{R}=\mathrm{H}$, Halogen, $\mathrm{NO}_{2}, \mathrm{CF}_{3}, \mathrm{Me}, \mathrm{CO}_{2} \mathrm{Me}, \mathrm{CN}$, OMe, etc.<smiles></smiles>

图式 46 铱催化亚胺基导向的芳环邻位 $\mathrm{C}-\mathrm{H}$ 键选择性磺酰 胺化反应

Scheme 46 Iridium-catalyzed direct ortho-C $-\mathrm{H}$ sulfonamidation of arylimines and $N$-sulfonyl arylimines

2018 年, Samanta 课题组 ${ }^{[77]}$ 报道了铱催化异喹啉酮 的选择性磺酰胺化反应. 当底物 $\mathrm{N}$ 上连吡啶基时, 吡啶 基起主要导向作用, 从而实现 3-位选择性磺酰胺化; 底 物 $\mathrm{N}$ 上连氢或甲基时，羰基起主要导向作用，从而实现 8-位选择性磺酰胺化(Scheme 47).

\section{2 .3 钓(II)催化}

2013 年 Chang 课题组 ${ }^{[78]}$ 对钉催化的芳环 $\mathrm{C}-\mathrm{H}$ 键 磺酰胺化反应进行了系统的研究. 发现二价钉络合物 

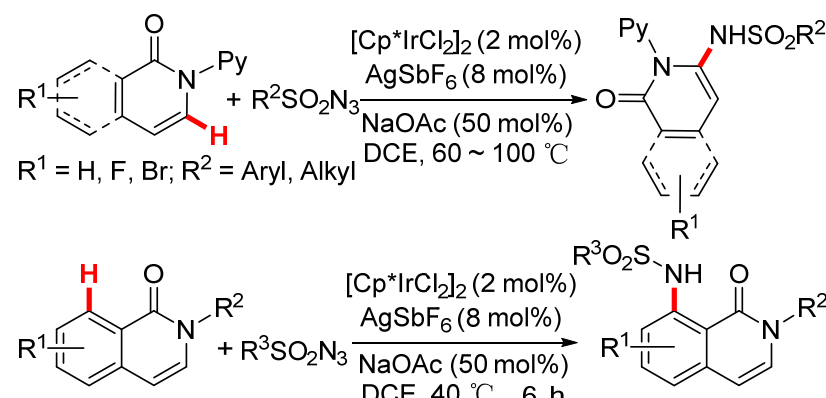

$\mathrm{R}^{1}=\mathrm{H}, \mathrm{CN}$, Alkenyl, Alkynyl, Aryl, etc.; $\mathrm{R}^{2}=\mathrm{Me}, \mathrm{H} ; \mathrm{R}^{3}=$ Alkyl, Aryl

图式 47 铱催化异喹啉酮的 $\mathrm{C}-\mathrm{H}$ 键选择性磺酰胺化反应 Scheme 47 Iridium(III)-catalyzed regiocontrolled direct sulfonamidation of Isoquinolones

$\left[\mathrm{RuCl}_{2}(p \text {-cymene })\right]_{2}$ 能催化各类官能团导向的芳环邻位 $\mathrm{C}-\mathrm{H}$ 键磺酰胺化反应. 当导向基团为酰胺基时, $\left[\mathrm{RuCl}_{2} \text { (p-cymene) }\right]_{2} / \mathrm{AgNTf}_{2}$ 催化体系能高效地促进该反 应进行，产率最高可达 95\%; 当导向基团为酮羰基时， 只要在上述催化体系中添加 $20 \mathrm{~mol} \%$ 的醋酸钠, 磺酰胺 化反应同样能高效地进行, 产率最高可达 $97 \%$; 当导向 基团为吡啶基、吡唑基等杂环时, $\left[\mathrm{RuCl}_{2} \text { ( } p \text {-cymene) }\right]_{2} /$ $\mathrm{AgSbF}_{6}$ 体系的催化效果更佳(Scheme 48). 几乎同时,

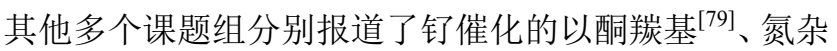

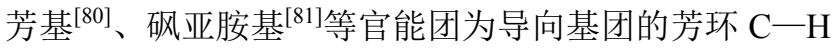
键磺酰胺化反应.

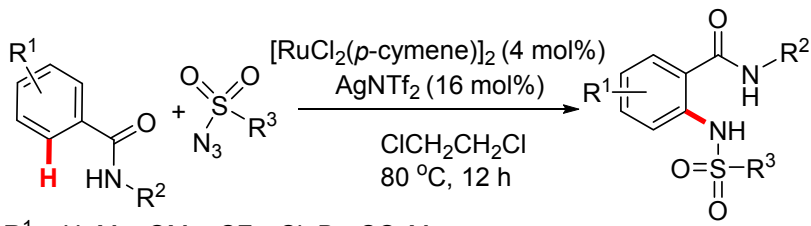

$\mathrm{R}^{1}=\mathrm{H}, \mathrm{Me}, \mathrm{OMe}, \mathrm{CF}_{3}, \mathrm{Cl}, \mathrm{Br}, \mathrm{CO}_{2} \mathrm{Me}$, etc. $\mathrm{R}^{2}=$ alkyl; $\mathrm{R}^{3}=$ Alkyl, Aryl

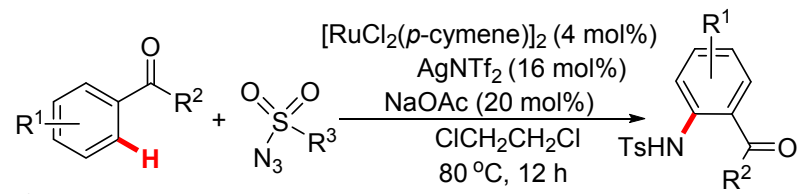

$\mathrm{R}^{1}=\mathrm{H}, \mathrm{Me}, \mathrm{OMe}$, Halogen, $\mathrm{CO}_{2} \mathrm{Me}, \mathrm{OH}$, etc. up to $97 \%$ yield

$\mathrm{R}^{2}=$ Alkyl; Aryl

$\mathrm{R}^{3}=$ Alkyl, Aryl

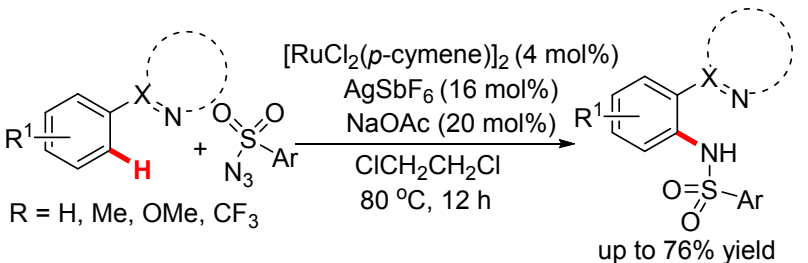

图式 48 钉催化芳环 $\mathrm{C}-\mathrm{H}$ 键磺酰胺化反应

Scheme 48 Ruthenium-catalyzed direct $\mathrm{C}-\mathrm{H}$ sulfonamidation of arenes

钉催化的芳环 $\mathrm{C}-\mathrm{H}$ 键磺酰胺化反应具有催化剂相 对廉价, 反应条件温和, 底物普适性强等优点, 其反应
机理如 Scheme 49 所示 ${ }^{[78]}$. $\left[\mathrm{RuCl}_{2}(p \text {-cymene })\right]_{2}$ 与 $\mathrm{AgNTf}_{2}$ 反应产生催化剂 $\left[\mathrm{Ru}(\mathrm{OAc})\left(p\right.\right.$-cymene)][NTf $\left.\mathrm{N}_{2}\right]$, 接着与底 物络合产生中间体 52, 进而与 $\mathrm{TsN}_{3}$ 络合生成中间体 $\mathbf{5 3}$ 、 脱氮气产生中间体 $\mathbf{5 4}$, 最后进行质子化脱金属反应生 成产物并使催化剂再生.

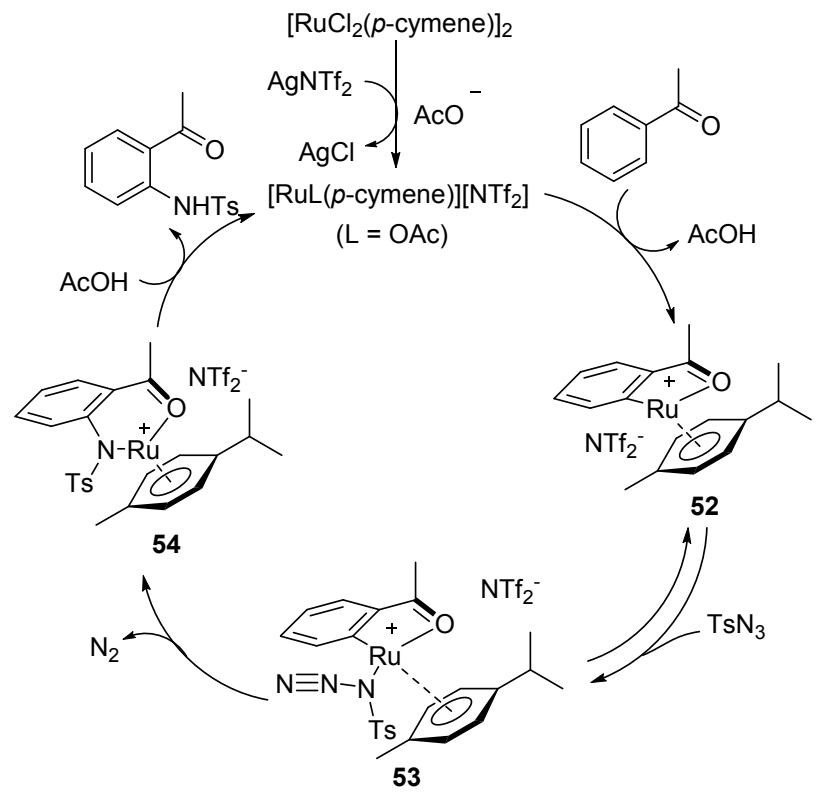

图式 49 钉催化以磺酰叠氮为氮源的芳环 $\mathrm{C}-\mathrm{H}$ 键磺酰胺化 反应机理

Scheme 49 Proposed reaction pathway of ruthenium-catalyzed direct $\mathrm{C}-\mathrm{H}$ sulfonamidation of arenes

\section{5 过渡金属催化的芳环磺酰胺化反应在药物及 其中间体合成中的应用}

近年来，越来越多的过渡金属催化的芳环磺酰胺化 反应被应用于药物及其中间体的合成中. NS5B 抑制剂 能够有效抑制丙肝病毒(HCV) RNA 聚合酶活性，是治 疗丙肝的一类重要药物. 2018 年, Leitch 课题组 ${ }^{[28]}$ 利用 铜催化芳基硼酸的磺酰胺化反应实现了 NS5B 抑制剂 GSK8175 的合成关键中间体 55 的合成. 该反应条件温 和，操作简单，适合于工业生产(Scheme 50).

2019 年 Shekhar 课题组 ${ }^{[82]}$ 以钯催化的全氟丁磺酸酯 与甲磺酰胺的偶联反应为关键步骤实现了抗丙肝病毒 药物 dasabuvir 的公斤级别的合成新方法. 该方法以 $\mathrm{Pd}_{2}(\mathrm{dba})_{3}$ 为催化剂, 环膦化合物 $\mathbf{5 c}$ 为配体, $\mathrm{K}_{3} \mathrm{PO}_{4}$ 为碱, 具有催化剂用量低、反应条件温和、反应试剂廉价易得、 反应中避免了使用致突变的磺酰氯和芳香胺等优点，成 为了 dasabuvir 的第二代工业合成新方法(Scheme 51).

\section{6 结论和展望}

综上所述，有机化学家们对过渡金属催化的芳环磺 酰胺化反应进行了深入研究，发展了包括: (1) Pd、 $\mathrm{Cu}$ 催 
<smiles>CS(=O)(=O)Nc1cc2oc(-c3ccc(F)cc3)c(C(=O)O)c2cc1C1CC1</smiles><smiles>COC(=O)c1cc(Br)cc(Cl)c1Br</smiles>

(1) $\mathrm{Cu}(\mathrm{MeCN})_{4} \mathrm{PF}_{6}$ (0.6 equiv.) Et ${ }_{3} \mathrm{~N}$ (16 equiv.) $\mathrm{MeCN}(225 \mathrm{~mL})$ $10{ }^{\circ} \mathrm{C}, 5 \% \mathrm{O}_{2}, 48 \mathrm{~h}$

(2) $\mathrm{MeNH}_{2}, \mathrm{THF}$, toluene
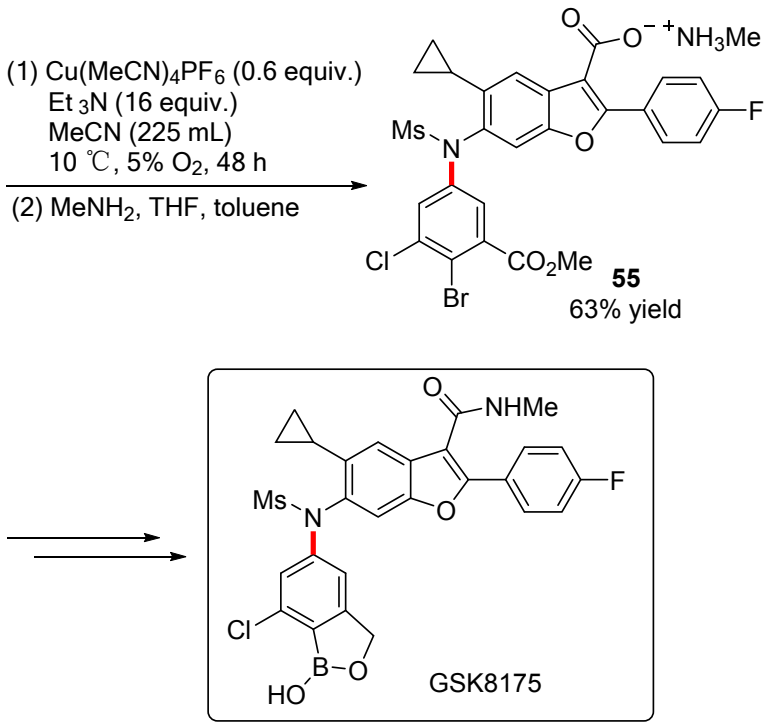

图式 50 Chan-Lam 偶联反应在 NS5B 抑制剂 GSK8175 的合 成中的应用

Scheme 50 Application of the Chan-Lam coupling reaction in the synthesis of NS5B inhibitor GSK8175<smiles>COc1c(-c2ccc3cc(OC(F)(F)F)ccc3c2)cc(-n2ccc(=O)[nH]c2=O)cc1C(C)(C)C</smiles><smiles>COc1c(-c2ccc3cc(NS(C)(=O)=O)ccc3c2)cc(-n2ccc(=O)[nH]c2=O)cc1C(C)(C)C</smiles><smiles>[R16]c1cc(C(C)C)cc(P)c1-c1c(OC)ccc(OC)c1PC(C)(C)CC1(CC2(CC(C)(C)C)OCCO2)OCCO1</smiles>

图式 51 Dasabuvir 公斤级合成新方法

Scheme 51 Second-generation route for synthesis of dasabuvir on multikilogram scale

化的卤代芳烃的磺酰胺化反应，(2) $\mathrm{Cu}$ 催化的芳基硼酸
的磺酰胺化反应，(3) $\mathrm{Pd} 、 \mathrm{Cu}$ 等催化的 $\mathrm{C}_{\mathrm{Ar}}-\mathrm{H}$ 键活化/ $\mathrm{C}-\mathrm{N}$ 偶联反应，(4) $\mathrm{Rh} 、 \mathrm{Ir} 、 \mathrm{Ru}$ 等催化的 $\mathrm{C}_{\mathrm{Ar}}-\mathrm{H}$ 键氮 宾插入反应等多种类型的反应. 但是过渡金属催化的磺 酰胺化反应仍然面临一些问题，例如铜催化卤代芳烃与 磺酰胺的偶联反应需要较高的反应温度和较大的催化 剂用量, 钯催化的卤代芳烃与磺酰胺的偶联反应需要使 用昂贵、有毒的膦配体, 铑、铱、钉、钯等过渡金属价 格昂贵, 大多数反应需要在有机溶剂中进行, 磺酰叠氮 化合物具有潜在的爆炸性等. 因此，发展更加绿色、廉 价、高效、温和的磺酰胺化反应，拓宽、拓广此类反应 在磺酰胺类药物中的应用将是未来研究的方向.

\section{References}

[1] (a) Hao, G.-F.; Yang, G.-F. Chin. J. Org. Chem. 2008, 28, 1545 (in Chinese).

(郝格非，杨光富，有机化学, 2008, 28, 1545.)

(b) He, S.-C.; Ponmani, J.; Avula, S.; Wang, X.-L.; Zhang, H.-Z.; Zhou, C.-H. Sci. Sin. Chim. 2016, 46, 823 (in Chinese).

(何世超, Jeyakkumar, P., Rao, A. S., 王宪龙, 张慧珍, 周成合, 中国科学: 化学, 2016, 46, 823.)

(c) He, S.-C. MS Thesis, Southwest University, Chongqing, 2017 (in Chinese).

(何世超，硕士论文，西南大学，重庆，2017.)

(d) Liu, Y. MS Thesis, Zhengzhou University, Zhengzhou, 2017 (in Chinese).

(刘英超，硕士论文，郑州大学，郑州，2017.)

(e) Che, C.; Hu, Y.; Ding, S.; Xiao, Y.; Li, J.; Qin, Z. Chin. J. Org. Chem. 2019, 39, 419 (in Chinese).

(车传亮, 胡益敏, 丁珊珊, 肖玉梅, 李佳奇, 覃兆海, 有机化学, 2019, 39, 419.)

[2] (a) Skipper, P. L.; Kim, M. Y.; Sun, H. L.; Wogan, G. N.; Tannenbaum, S. R. Carcinogenesis 2010, 31, 50.

(b) Snodin, D. J. Org. Process Res. Dev. 2010, 14, 960.

[3] Yasuhara, A.; Kameda, M.; Sakamoto, T. Chem. Pharm. Bull. 1999, 47, 809 .

[4] Fang, S.; Lü, M.; Long, Y.; Yang, D. Chin. J. Org. Chem. 2011, 31, 1573 (in Chinese). (方晒，吕梅香，龙玉华，杨定乔，有机化学，2011，31，1573.)

[5] (a) Sambiagio, C.; Marsden, S. P.; Blacker, A. J.; McGowan, P. C. Chem. Soc. Rev. 2014, 43, 3525.

(b) Monnier, F.; Taillefer, M. Angew. Chem., Int. Ed. 2009, 48, 6954.

(c) Ma, D.; Cai, Q. Acc. Chem. Res. 2008, 41, 1450.

(d) Evano, G.; Blanchard, N.; Toumi, M. Chem. Rev. 2008, 108, 3054 .

(e) Deng, W.; Liu, L.; Guo, Q.-X. Chin. J. Org. Chem. 2004, 24, 150 (in Chinese)

(邓维, 刘否, 郭庆祥, 有机化学, 2004, 24, 150.)

(f) Ley, S. V.; Thomas, A. W. Angew. Chem., Int. Ed. 2003, 42, 5400.

[6] Wolfe, J. P.; Rennels, R. A.; Buchwald, S. L. Tetrahedron 1996, 52, 7525.

[7] (a) Yin, J.; Buchwald, S. L. Org. Lett. 2000, 2, 1101.

(b) Yin, J.; Buchwald, S. L. J. Am. Chem. Soc. 2002, 124, 6043.

[8] Burton, G.; Cao, P.; Li, G.; Rivero, R. Org. Lett. 2003, 5, 4373.

[9] Ikawa, T.; Barder, T. E.; Biscoe, M. R.; Buchwald, S. L. J. Am. Chem. Soc. 2007, 129, 13001.

[10] Hicks, J. D.; Hyde, A. M.; Cuezva, A. M.; Buchwald, S. L. J. Am. Chem. Soc. 2009, 131, 16720.

[11] Rosen, B. R.; Ruble, J. C.; Beauchamp, T. J.; Navarro, A. Org. Lett 2011, 13, 2564.

[12] Laffoon, S. D.; Chan, V. S.; Fickes, M. G.; Kotecki, B. J.; Ickes, 
A.; Henle, J.; Napolitano, J. G.; Franczyk, T. S.; Dunn, T. B.; Barnes, D. M.; Haight, A. R.; Henry, R. F.; Shekhar, S. ACS Catal. 2019, 9, 11691

[13] He, H.; Wu, Y.-J. Tetrahedron Lett. 2003, 44, 3385.

[14] Tan, B. Y.-H.; Teo, Y.-C.; Seow, A.-H. Eur. J. Org. Chem. 2014, 2014, 1541.

[15] Deng, W.; Liu, L.; Zhang, C.; Liu, M.; Guo, Q.-X. Tetrahedron Lett. 2005, 46, 7295.

[16] Baffoe, J.; Hoe, M. Y.; Toure, B. B. Org. Lett. 2010, 12, 1532.

[17] Wang, X.; Guram, A.; Ronk, M.; Milne, J. E.; Tedrow, J. S.; Faul, M. M. Tetrahedron Lett. 2012, 53, 7.

[18] Han, X. Tetrahedron Lett. 2010, 51, 360

[19] Kim, T.; McCarver, S. J.; Lee, C.; MacMillan, D. W. C. Angew. Chem., Int. Ed. 2018, 57, 3488.

[20] For selected reviews, see:

(a) Duan, X.; Liu, N.; Wang, J.; Ma, J. Chin. J. Org. Chem. 2019, 39, 661 (in Chinese).

(段希炎, 刘宁, 王佳, 马军营, 有机化学, 2019, 39, 661.)

(b) Ma, X.; Liu, F.; Mo, D. Chin. J. Org. Chem. 2017, 37, 1069 (in Chinese).

(马小盼, 刘凤萍, 莫冬亮, 有机化学, 2017, 37, 1069.)

(c) Sanjeeva Rao, K.; Wu, T.-S. Tetrahedron 2012, 68, 7735.

(d) Qiao, J.; Lam, P. Synthesis 2010, 829.

[21] For recent examples, see:

(a) Jiao, J.-W.; Bi, H.-Y.; Zou, P.-S.; Wang, Z.-X.; Liang, C.; Mo, D.-L. Adv. Synth. Catal. 2018, 360, 3254.

(b) Mo, X.-L.; Chen, C.-H.; Liang, C.; Mo, D.-L. Eur. J. Org. Chem. 2018, 2018, 150 .

(c) Vantourout, J. C.; Miras, H. N.; Isidro-Llobet, A.; Sproules, S.; Watson, A. J. J. Am. Chem. Soc. 2017, 139, 4769.

(d) Shi, W.-M.; Liu, F.-P.; Wang, Z.-X.; Bi, H.-Y.; Liang, C.; Xu, L.-P.; Su, G.-F.; Mo, D.-L. Adv. Synth. Catal. 2017, 359, 2741.

(e) Chen, C. H.; Liu, Q. Q.; Ma, X. P.; Feng, Y.; Liang, C.; Pan, C. X.; Su, G. F.; Mo, D. L. J. Org. Chem. 2017, 82, 6417.

[22] Chan, D. M. T.; Monaco, K. L.; Wang, R.-P.; Winters, M. P. Tetrahedron Lett. 1998, 39, 2933.

[23] Lam, P. Y. S.; Vincent, G.; Clark, C. G.; Deudon, S.; Jadhav, P. K. Tetrahedron Lett. 2001, 42, 3415.

[24] Lan, J.-B.; Zhang, G.-L.; Yu, X.-Q.; You, J.-S.; Chen, L.; Yan, M.; Xie, R.-G. Synlett 2004, 1095

[25] Pan, C.; Cheng, J.; Wu, H.; Ding, J.; Liu, M. Synth. Commun. 2009, 39, 2082.

[26] Kantam, M. L.; Neelima, B.; Reddy, C. V.; Neeraja, V. J. Mol. Catal. A: Chem. 2006, 249, 201.

[27] (a) Azarifar, D.; Soleimanei, F. RSC Adv. 2014, 4, 12119.

(b) Nasrollahzadeh, M.; Ehsani, A.; Maham, M. Synlett 2014, 25, 505.

[28] Vantourout, J. C.; Li, L.; Bendito-Moll, E.; Chabbra, S.; Arrington, K.; Bode, B. E.; Isidro-Llobet, A.; Kowalski, J. A.; Nilson, M. G.; Wheelhouse, K. M. P.; Woodard, J. L.; Xie, S.; Leitch, D. C.; Watson, A. J. B. ACS Catal. 2018, 8, 9560

[29] Moon, S. Y.; Nam, J.; Rathwell, K.; Kim, W. S. Org. Lett. 2014, 16, 338

[30] Ouyang, B.; Liu, D.; Xia, K.; Zheng, Y.; Mei, H.; Qiu, G. Synlett 2018, 29, 111

[31] Ouyang, B.; Zheng, Y.; Liu, Y.; Liu, F.; Yao, J.; Peng, Y. Tetrahedron Lett. 2018, 59, 3694.

[32] (a) Louillat, M. L.; Patureau, F. W. Chem. Soc. Rev. 2014, 43, 901. (b) Park, Y.; Kim, Y.; Chang, S. Chem. Rev. 2017, 117, 9247.

[33] Thu, H. Y.; Yu, W. Y.; Che, C. M. J. Am. Chem. Soc. 2006, 128, 9048 .

[34] Youn, S. W.; Bihn, J. H.; Kim, B. S. Org. Lett. 2011, 13, 3738.

[35] Xiao, B.; Gong, T. J.; Xu, J.; Liu, Z. J.; Liu, L. J. Am. Chem. Soc. 2011, 133, 1466 .

[36] Chen, X.; Hao, X. S.; Goodhue, C. E.; Yu, J. Q. J. Am. Chem. Soc. 2006, 128,6790 .

[37] John, A.; Nicholas, K. M. J. Org. Chem. 2011, 76, 4158.

[38] Shang, M.; Sun, S. Z.; Dai, H. X.; Yu, J. Q. J. Am. Chem. Soc.
2014, 136, 3354.

[39] Lee, W. C.; Shen, Y.; Gutierrez, D. A.; Li, J. J. Org. Lett. 2016, 18, 2660 .

[40] Song, C.; Wang, T.; Yu, T.; Cui, D. M.; Zhang, C. Org. Biomol. Chem. 2017, 15, 7212 .

[41] Meyer, A. U.; Berger, A. L.; König, B. Chem. Commun. 2016, 52, 10918

[42] Tong, K.; Liu, X.; Zhang, Y.; Yu, S. Chem.-Eur. J. 2016, 22, 15669

[43] Gao, Y.; Chen, S.; Lu, W.; Gu, W.; Liu, P.; Sun, P. Org. Biomol. Chem. 2017, 15, 8102 .

[44] Kwart, H.; Khan, A. A. J. Am. Chem. Soc. 1967, 89, 1951.

[45] Díaz-Requejo, M. M.; Belderraín, T. S. R.; Nicasio, M. C.; Trofimenko, S.; Pérez J. P. J. Am. Chem. Soc. 2003, 125, 12078.

[46] Hamilton, C. W.; Laitar, D. S.; Sadighi, J. P. Chem. Commun. 2004, 1628.

[47] He, L.; Chan, P. W.; Tsui, W. M.; Yu, W. Y.; Che, C. M. Org. Lett. 2004, 6, 2405.

[48] Fructos, M. R.; Trofimenko, S.; Diaz-Requejo, M. M.; Perez, P. J. J. Am. Chem. Soc. 2006, 128, 11784.

[49] Li, Z.; Capretto, D. A.; Rahaman, R. O.; He, C. J. Am. Chem. Soc. 2007, 129, 12058.

[50] Zhao, H.; Shang, Y.; Su, W. Org. Lett. 2013, 15, 5106.

[51] Li, H.; Deng, H. Synthesis 2017, 49, 2711.

[52] Dong, Y.; Sun, S.; Yu, J.-t.; Cheng, J. Tetrahedron Lett. 2019, 60, 1349.

[53] (a) Kim, S. H.; Park, S. H.; Choi, J. H.; Chang, S. Chem. Asian J. 2011, 6, 2618

(b) Lu, P.; Wang, Y. Chem. Soc. Rev. 2012, 41, 5687.

(c) Santiago, J. Synlett 2015, 26, 2323.

(d) Zhang, W.; Xu, W.; Kuang, C. Chin. J. Org. Chem. 2015, 35, 2059 (in Chinese). (张文生，许文静，匡春香，有机化学, 2015, 35, 2059.)

[54] Kim, J. Y.; Park, S. H.; Ryu, J.; Cho, S. H.; Kim, S. H.; Chang, S. J. Am. Chem. Soc. 2012, 134, 9110.

[55] Park, S. H.; Kwak, J.; Shin, K.; Ryu, J.; Park, Y.; Chang, S. J. Am. Chem. Soc. 2014, 136, 2492.

[56] Shi, J.; Zhou, B.; Yang, Y.; Li, Y. Org. Biomol. Chem. 2012, 10, 8953.

[57] Yu, D. G.; Suri, M.; Glorius, F. J. Am. Chem. Soc. 2013, 135, 8802.

[58] Zhang, C.; Tang, C.; Jiao, N. Chem. Soc. Rev. 2012, 41, 3464

[59] Wang, H.; Yu, Y.; Hong, X.; Tan, Q.; Xu, B. J. Org. Chem. 2014, $79,3279$.

[60] Jia, X.; Han, J. J. Org. Chem. 2014, 79, 4180

[61] Zhang, C.; Zhou, Y.; Deng, Z.; Chen, X.; Peng, Y. Eur. J. Org. Chem. 2015, 2015, 1735.

[62] Lee, D.; Kim, Y.; Chang, S. J. Org. Chem. 2013, 78, 11102.

[63] Figg, T. M.; Park, S.; Park, J.; Chang, S.; Musaev, D. G. Organometallics 2014, 33, 4076.

[64] Gwon, D.; Lee, D.; Kim, J.; Park, S.; Chang, S. Chem.-Eur. J. 2014, $20,12421$.

[65] Hwang, H.; Kim, J.; Jeong, J.; Chang, S. J. Am. Chem. Soc. 2014, 136,10770 .

[66] Kim, J.; Chang, S. Angew. Chem., Int. Ed. 2014, 53, 2203

[67] Shin, K.; Chang, S. J. Org. Chem. 2014, 79, 12197.

[68] Hou, W.; Yang, Y.; Ai, W.; Wu, Y.; Wang, X.; Zhou, B.; Li, Y. Eur. J. Org. Chem. 2015, 2015, 395.

[69] Lee, D.; Chang, S. Chem.-Eur. J. 2015, 21, 5364.

[70] Pi, C.; Cui, X.; Wu, Y. J. Org. Chem. 2015, 80, 7333.

[71] Kim, Y.; Park, J.; Chang, S. Org. Lett. 2016, $18,1892$.

[72] Xu, L.; Tan, L.; Ma, D. J. Org. Chem. 2016, 81, 10476.

[73] Song, Z.; Antonchick, A. P. Org. Biomol. Chem. 2016, 14, 4804

[74] Li, Y.; Feng, Y.; Xu, L.; Wang, L.; Cui, X. Org. Lett. 2016, 18, 4924.

[75] Zhang, Y. F.; Wu, B.; Shi, Z. J. Chem.-Eur. J. 2016, 22, 17808.

[76] Mu, D.; Wang, X.; Chen, G.; He, G. J. Org. Chem. 2017, 82, 4497.

[77] Das, D.; Samanta, R. Adv. Synth. Catal. 2018, 360, 379.

[78] Kim, J.; Kim, J.; Chang, S. Chem.-Eur. J. 2013, 19, 7328. 
[79] (a) Bhanuchandra, M.; Yadav, M. R.; Rit, R. K.; Rao Kuram, M.; Sahoo, A. K. Chem. Commun. 2013, 49, 5225.

(b) Zheng, Q. Z.; Liang, Y. F.; Qin, C.; Jiao, N. Chem. Commun. 2013, 49,5654 .

[80] Thirunavukkarasu, V. S.; Raghuvanshi, K.; Ackermann, L. Org. Lett. 2013, 15, 3286.
[81] Yadav, M. R.; Rit, R. K.; Sahoo, A. K. Org. Lett. 2013, 15, 1638.

[82] Barnes, D. M.; Shekhar, S.; Dunn, T. B.; Barkalow, J. H.; Chan, V. S.; Franczyk, T. S.; Haight, A. R.; Hengeveld, J. E.; Kolaczkowski, L.; Kotecki, B. J.; Liang, G.; Marek, J. C.; McLaughlin, M. A.; Montavon, D. K.; Napier, J. J. J. Org. Chem. 2019, 84, 4873.

(Lu, Y.) 